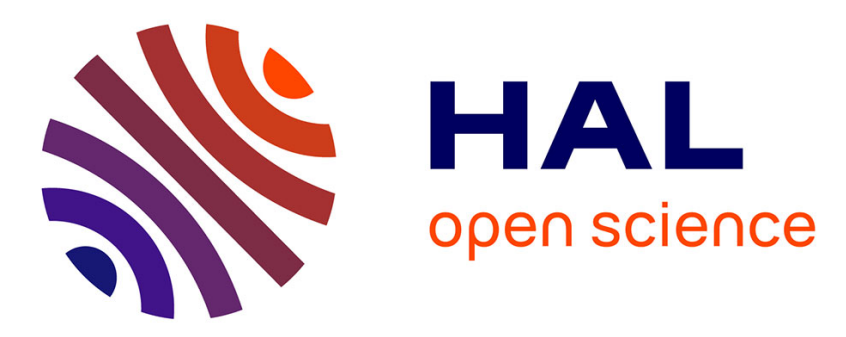

\title{
A dynamic equilibrium model of imperfectly integrated financial markets
}

Nicolas Coeurdacier, Stéphane Guibaud

\section{To cite this version:}

Nicolas Coeurdacier, Stéphane Guibaud. A dynamic equilibrium model of imperfectly integrated financial markets. 2005. halshs-00590775

\section{HAL Id: halshs-00590775 \\ https://shs.hal.science/halshs-00590775}

Preprint submitted on 5 May 2011

HAL is a multi-disciplinary open access archive for the deposit and dissemination of scientific research documents, whether they are published or not. The documents may come from teaching and research institutions in France or abroad, or from public or private research centers.
L'archive ouverte pluridisciplinaire HAL, est destinée au dépôt et à la diffusion de documents scientifiques de niveau recherche, publiés ou non, émanant des établissements d'enseignement et de recherche français ou étrangers, des laboratoires publics ou privés. 
WORKING PAPER № 2005 - 24

\author{
A Dynamic Equilibrium Model \\ of Imperfectly Integrated Financial Markets
}

Nicolas Coeurdacier

Stéphane Guibaud

Codes JEL : G12, G15, G11, F36

Mots clés : Asset Pricing, Financial Integration, Home Bias in Portfolio, International Stock Returns Correlations, Asymmetric Taxation, Investors Heterogeneity, Stochastic Pareto-Negishi Weight 


\title{
A Dynamic Equilibrium Model
}

\section{of Imperfectly Integrated Financial Markets}

\author{
Nicolas Coeurdacier *
}

\author{
Stéphane Guibaud ${ }^{\dagger \ddagger}$
}

\begin{abstract}
We build a continous-time general equilibrium model of a two-country, pure-exchange economy featuring taxes on the repatriation of dividends. We find approximate closed-form expressions for asset prices, returns joint dynamics and equity portfolios, thus giving a full description of equilibrium in-between the polar cases of perfect integration and full segmentation. We show that large home bias in portfolios can result from small frictions on international financial markets. The reason is that, partly due to portfolio rebalancing, the international correlation of returns is very high - making assets close substitutes and implying that slight frictions have a dramatic effect on portfolio composition.
\end{abstract}

Keywords : Asset Pricing, Financial Integration, Home Bias in Portfolio, International Stock Returns Correlations, Asymmetric Taxation, Investors Heterogeneity, Stochastic Pareto-Negishi Weight

JEL Codes : G12, G15, G11, F36

*Paris-Jourdan Sciences Economiques, 48 boulevard Jourdan, 75014 Paris. E-mail: nicolas.coeurdacier@ens.fr

$\dagger$ Paris-Jourdan Sciences Economiques, 48 boulevard Jourdan, 75014 Paris. E-mail: stephane.guibaud@ens.fr

$\ddagger$ We are grateful to Daniel Cohen, Bernard Dumas, Philippe Martin and Richard Portes for their comments and suggestions. We also thank all the participants at the Federation Jourdan Lunch Seminar. This paper will be presented at the Econometric Society World Congress in London in August 2005. 


\section{Introduction}

In this paper, we build a continuous-time general equilibrium model of a two-country, pure-exchange economy with imperfectly integrated financial markets. We have a unique perishable good, a "Lucas tree" in each country and taxes on the repatriation of dividends which capture the imperfect integration of capital markets. Our main achievement is to determine endogenously both asset substituability (i.e. asset returns correlation) and portfolios composition for different degrees of financial integration. This constitutes a first attempt to give a full description of equilibrium in-between the polar cases of perfect integration and total segmentation. We believe our setting is appropriate to make sense of a) the extent of international portfolio diversification, b) asset prices joint dynamics and c) their evolution over the past decades.

The broad stylized facts that are in the background of this work are related to the large increase in international financial linkages that occurred in the last twenty years. Over this period, industrialized countries and emerging markets opened their capital account to foreign investors and many obstacles to international capital flows were relaxed. This wave of institutional financial opening led to a huge rise in cross-border asset holdings (see Lane et al. [2003]). Of course, countries do still exhibit a substantial "home bias", but less substantial than as first documented by French and Poterba [1991] : while US investors held $94 \%$ of the US stock market in 1989, this number had decreased to $88 \%$ in 2001 (see Amadi [2004] and Chan et al. [2005]). On the asset prices side, there is massive evidence of a steady increase in comovements between countries: for instance, since the early 1970's the correlation between US monthly stock returns (on the S\&P500 index) and returns on a synthetic non-US world index has gained 0.1 each decade, rising continuously from 0.4 in 1970 to 0.71 in $200{ }^{1}$. Even though return correlation cannot be interpreted unambiguously as a measure of integration without making reference to fundamentals, the observed increase in prices comovements is probably related to the process of financial integration. Bekaert and Harvey [2000] and Walti [2004] find evidence of a positive relationship between the level of financial market integration and stock return correlations.

Overall, it seems that international financial markets are in a loose sense neither totally segmented

\footnotetext{
${ }^{1}$ In August 2004, the correlation (over a 5-year window) had risen up to 0.82 .
} 
nor perfectly integrated. But where in-between do we stand? Another way to put it is the following: If markets were perfectly integrated, all investors would hold the same portfolio, the "world market portfolio", independently of their country ${ }^{2}$ - but do the large deviations from this benchmark case found in the data ${ }^{3}$ allow us to say that we are "far" from a perfectly integrated world? Addressing this question in a proper way calls for a rigorous definition of the notion of "financial integration", which amounts to the choice of a particular metric.

Assessing "integration" can be done by looking at several observable variables: prices, returns, portfolios, consumption, regulations... Based on these observations, the literature typically performs binary tests which take either perfect integration or full segmentation as a null hypothesis ${ }^{4}$. The question we ask is rather: what should the size of underlying impediments to cross-border equity holdings be to match the empirical evidence on international asset portfolios? Our contribution is to build a model in which this question is meaningful and can be given a proper answer through calibration. In our model, financial markets are institutionally open and they are "pricewise" perfectly integrated (in the sense of Chen and Knez [1995], or Rose [2003]): both the law of one price and no-arbitrage prevail on financial markets. But in terms of portfolios, markets appear far from being integrated.

What is the view of the world resulting from our calibration exercise? We believe international financial markets are characterized by a combination of high asset substituability (following from high fundamental comovements) and small barriers to cross-border holdings resulting in substantial home bias in porfolios. An important message conveyed by this paper is the following: deviations from the world market portfolio per se are not informative on the size of frictions on financial markets - this is all conditional on asset substituability. In a world characterized by high international comovements, portfolios can exhibit large deviations from the "world market portfolio" even though obstacles to foreign equity holdings are quite small.

\footnotetext{
2 In theory, this proposition only holds under quite restrictive assumptions: it would fail to be true if investors faced idiosyncratic shocks unhedgeable because of some market incompleteness - or in presence of some information asymetries. Deviations from purchasing power parity (possibly related to trade costs) constitute another source of departure from the benchmark if assets pay in nominal terms (Adler and Dumas [1983]).

3 In particular, countries do invest much more in geographically close economies (Portes and Rey [1999]) or in their trading partner countries (Aviat and Coeurdacier [2004]).

4 For instance, see tests of the international asset pricing model, e.g. Dumas and Solnik [1995]. A notable exception is Chen and Knez [1995] who provide a non parametric measure of integration by taking the distance between state-prices measures.
} 
Throughout the paper, we present qualitative and quantitative results on the impacts of "financial integration", by which we mean a decrease in impediments to foreign equity holdings. In our framework, as taxes on the repatriation of dividends decrease, asset prices increase (consistently with evidence in Henry [2000] and Bekaert [2000]), international returns correlation and cross-country equity holdings both also increase (the latter effect is of first-order, the former of second-order) while asset prices volatility diminishes (also a second-order effect). The overall impact of financial integration on the cost of funds is not clear-cut, depending on the respective size of the decrease in risk premium (due to a better access to diversification opportunities) and of the increase in the risk free rate (due to lower precautionary saving). This may explain why the negative relationship between the cost of capital and market integration has been extremely difficult to find in the data (Stulz [1999]). Also, as a by-product of our model, we derive a gravity equation for trade in financial claims, giving theoretical foundations to recent empirical papers in international finance (see Portes and Rey [2005], Aviat and Coeurdacier [2004], Lane and Milesi-Feretti [2004], Coeurdacier and Guibaud [2004]).

Technically, the difficulty of our model consists in solving for a dynamic general equilibrium with heterogenous investors, the heterogeneity being induced by differential taxation. As a consequence of this feature, the equilibrium allocation is not Pareto efficient (this is like in Basak and Gallmeyer [2003]) and we cannot use the pricing kernel of a single representative investor holding the world market portfolio to price assets. In order to solve for equilibrium we use a stochastic Pareto-Negishi weight à la Cuoco and He [1994]. Under the assumption of logarithmic utility and lognormal dividend processes in each country, we are able to give approximate closed-form expressions for asset prices, equity portfolios and assets returns joint dynamics, as functions of a few state-variables. We make Taylor expansions in the neighborhood of the case of perfect integration, for which Cochrane, Longstaff and Santa-Clara [2003] obtain exact closed-form expressions. In this way, we endogenously determine the joint dynamics of asset prices (given the dynamics followed by the fundamentals) and we can see how it is affected by a variation in obstacles to foreign equity holdings ${ }^{5}$.

In our model like in Cochrane, Longstaff and Santa-Clara [2003], asset prices joint dynamics are partly driven by "portfolio rebalancing". This mechanism induces the correlation of stock returns to be higher

\footnotetext{
5 We assume that fundamentals are not affected by the integration process - as could be the case due to specialization or more risk-taking as a response to new risk-sharing opportunities, a possibility emphasized in Obstfeld [1994].
} 
than the correlation of the "fundamentals" solely because some investors hold both assets. To catch the intuition for this mechanism, take the case of two countries and two assets, one in each country, with imperfectly correlated dividends and consider the impact on asset prices of a good shock on domestic dividends. If both markets are completely segmented, this good shock on the domestic asset will drive its price up without affecting the foreign asset price. If on the contrary both markets are perfectly integrated, the increase in the domestic asset price will lead the investor to rebalance part of her portfolio towards the foreign asset - because her exposure to domestic risk has increased with the increase in the domestic asset price. The required rate of return on the foreign asset decreases (because its diversification property are now more cherished) and the foreign asset price must increase to restore equilibrium ${ }^{6}$. This rebalancing effect naturally leads to more comovement between domestic and foreign asset prices than in the fullysegmented world. In-between the two polar cases, the same logic operates monotonously: the lower the frictions between two markets, the higher the comovements of their stock prices, for a given correlation of the fundamentals. We shall insist on the fact that the "portfolio rebalancing" effect, though spectacular for low levels of fundamental correlation and no friction on financial markets (the case emphasized by Cochrane et al. [2003]), is quantitatively small for a realistic calibration of the model parameters.

To our knowledge, a joint analysis of portfolio diversification and of the endogenous determination of asset prices dynamics in imperfectly integrated financial markets was lacking in the literature. Black [1974], Errunza and Losq [1985,1989], Eun and Jarakiramanan [1986], were studying the impact of international financial barriers on porfolio holdings and asset pricing in a static mean-variance framework, leaving no room to "portfolio rebalancing" effects. Actually, few papers in the literature adopt a multiasset setting and derive asset return processes from fundamental dynamics. Our theoretical contribution completes the analyses by Dumas, Harvey and Ruiz [2003] and Cochrane, Longstaff and Santa-Clara [2003] which both restrict their attention to the two polar cases of complete segmentation and perfect integration. The paper closest to our analysis is Bhamra [2002]: he considers situations of "intermediate integration", but he imposes constraints directly on the amount of wealth that can be invested abroad, which is unsatisfactory since what is important is precisely to understand why the amounts invested in foreign assets are low. Serrat [2001] is another example of a multi-asset dynamic general equilibrium

\footnotetext{
6 In Cochrane et al., it is typically true that the partial derivative of the price function of an asset with respect to the dividends of the other asset is positive, but it is not true in all states.
} 
asset-pricing model, but he restricts his focus on portfolios and he emphasizes the presence of non-tradable goods as the main source of home bias.

The remaining of the paper is organized as follows. Section 2 presents the setup of the model and gives a first characterization of equilibrium in the general case. Section 3 solves the model using Taylor expansions around the case of perfect risk-sharing and derives the implications of imperfect market integration for asset prices dynamics, portfolio allocations and the cost of capital. Section 4 is devoted to discussions and comments and section 5 concludes. The proofs of the main propositions are relegated in a separate appendix.

\section{The model}

\subsection{Setup}

We consider a continuous time economy with an infinite horizon. There are two countries, home $(H)$ and foreign $(F)$, and a single perishable good. Each country has a representative agent with utility functional

$$
U_{i t}=E_{t}\left[\int_{t}^{+\infty} e^{-\rho(s-t)} \log \left(c_{i s}\right) d s\right]
$$

where $c_{i s}$ is the consumption rate in country $i$ and $\rho$ is the common rate of time preference.

There are stocks in each country (in constant net supply normalized to one) giving a claim to an exogeneously specified positive dividend process $D_{i}$ following a geometric brownian motion:

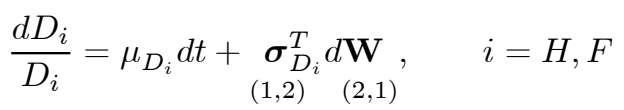

All uncertainty is generated by the 2-dimensional brownian motion $\mathbf{W}(t)$. We denote by $\eta$ the correlation of the two dividend growth rates, which we henceforth refer to as the "fundamental correlation"7 . Throughout, we use bold cases for vectors and matrices and $\mathbf{A}^{T}$ to denote the transpose of $\mathbf{A}$.

Investors from country $i$ are subject to an exogenous constant tax $\tau_{j}$ on the dividend received from stocks of country $j\left(0<\tau_{j}<1\right)^{8}$. Hence, a domestic agent who holds a unit of foreign stock receives the instantaneous dividend $\left(1-\tau_{F}\right) D_{F} d t$. When $\tau_{i}=0$, country $i$ is perfectly integrated to capital

\footnotetext{
7 We have: $\eta=\frac{\sigma_{D_{H} 1 \sigma_{D_{F}}+\sigma_{D_{H}{ }^{2} \sigma_{D_{F}}}}}{\sqrt{\left(\sigma_{D_{H}{ }^{2}}^{2}+\sigma_{D_{H^{2}}}^{2}\right)\left(\sigma_{D_{F}{ }^{2}}^{2}+\sigma_{D_{F}}^{2}\right)}}$.

${ }^{8}$ One might argue that the asymmetric taxation should also apply to capital gains. We have to use this simpler setup to make the model tractable.
} 
markets (whereas when $\tau_{i}$ is close enough to 1 , country $i$ is segmented). Asymmetric taxation is a real world feature and we believe that in this literal interpretation any number between $10 \%$ and $15 \%$ would be realistic. However, we mean this differential tax treatment between foreign and domestic dividends to capture more generally any barrier to cross-border equity holdings.

Besides the two risky assets, there is a "locally" riskless bond in zero net supply earning an interest rate $r$. The bond price satisfies

$$
\frac{d B}{B}=r d t
$$

The interest rate process - as well as the processes for the drift coefficients and diffusion vectors of asset prices to be defined below - will be determined in equilibrium.

We assume that taxes are redistributed to investors as endowments such that the following marketclearing condition holds at each instant in the goods market : $c_{H}+c_{F}=D_{H}+D_{F}$ (we will specify later the way we redistribute collected taxes in the economies). Finally, we call $D \equiv D_{H}+D_{F}$ the total endowment of the world economy. It is immediate from $(1)$ that $D(t)$ has the following dynamics:

$$
\begin{gathered}
\frac{d D}{D}=\underbrace{\left[\delta(t) \mu_{D_{H}}+(1-\delta(t)) \mu_{D_{F}}\right]}_{\equiv \mu_{D}} d t+\underbrace{\left[\delta(t) \boldsymbol{\sigma}_{D_{H}}^{T}+(1-\delta(t)) \boldsymbol{\sigma}_{D_{F}}^{T}\right]}_{\equiv \boldsymbol{\sigma}_{D}^{T}} d \mathbf{W} \\
\text { where } \delta(t) \equiv \frac{D_{H}(t)}{D_{H}(t)+D_{F}(t)}
\end{gathered}
$$

The variable $\delta$, which captures the relative size of the two economies, will be a key state-variable in the model.

\subsection{Admissible asset prices dynamics}

Due to differential taxation, a same stock does not have the same after-tax expected return for the two investors; but still, both investors have to agree on prices. This will be possible because investors, holding different portfolios, will not have the same perception of risk.

We will denote by $S_{H}$ the price of the domestic stock and $S_{F}$ the price of the foreign stock and we will assume that in equilibrium $S_{H}$ and $S_{F}$ both follow Ito processes. We denote by $\mu_{j}^{i}$ the after-tax total instantaneous expected return on asset $j$ for investor $i$ for $i \neq j$ and $\mu_{j}$ the after-tax total instantaneous expected return on the same asset for country $j$ investors. Hence adopting the point of view of the 
domestic investor, stock prices have to be such that:

$$
\begin{gathered}
d S_{H}=\left[\mu_{H} S_{H}-D_{H}\right] d t+S_{H}\left(\boldsymbol{\sigma}_{H}\right)^{T} d \mathbf{W} \\
d S_{F}=\left[\mu_{F}^{H} S_{F}-\left(1-\tau_{F}\right) D_{F}\right] d t+S_{F}\left(\boldsymbol{\sigma}_{F}^{H}\right)^{T} d \mathbf{W}
\end{gathered}
$$

But stock prices also have to be solution of the following stochastic differential equations:

$$
\begin{gathered}
d S_{H}=\left[\mu_{H}^{F} S_{H}-\left(1-\tau_{H}\right) D_{H}\right] d t+S_{H}\left(\boldsymbol{\sigma}_{H}^{F}\right)^{T} d \mathbf{W} \\
d S_{F}=\left[\mu_{F} S_{F}-D_{F}\right] d t+S_{F}\left(\boldsymbol{\sigma}_{F}\right)^{T} d \mathbf{W}
\end{gathered}
$$

Since investors have to agree on a same price, the following conditions must hold ${ }^{9}$ :

$$
\begin{gathered}
\mu_{H}-\mu_{H}^{F}=\tau_{H} \frac{D_{H}}{S_{H}} \quad \mu_{F}-\mu_{F}^{H}=\tau_{F} \frac{D_{F}}{S_{F}} \\
\boldsymbol{\sigma}_{H}=\boldsymbol{\sigma}_{H}^{F} \quad \boldsymbol{\sigma}_{F}^{H}=\boldsymbol{\sigma}_{F}
\end{gathered}
$$

We assume that the equilibrium price dynamics are such that markets are complete (the two assets are not redundant) and that no-arbitrage prevails, so that we can construct a well-defined after-tax state price density process for each investor. We will note $\xi_{i}(i=H, F)$ each investor-specific after-tax stateprice density process. In complete markets, we know that, for given asset prices dynamics, $\xi_{i}$ satisfies the following stochastic differential equation ${ }^{10}$ :

$$
d \xi_{i}=-\xi_{i}\left[r(t) d t+\boldsymbol{\theta}_{i}^{\mathbf{T}}(t) d \mathbf{W}(t)\right]
$$

where $\boldsymbol{\theta}_{i}$ represents investor $i$ 's "after-tax" market prices of risk:

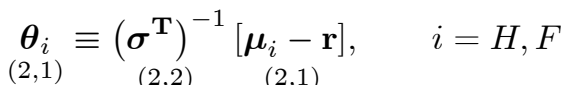

with $\boldsymbol{\mu}_{H}^{T} \equiv\left(\mu_{H}, \mu_{F}^{H}\right), \boldsymbol{\mu}_{F}^{T} \equiv\left(\mu_{H}^{F}, \mu_{F}\right)$ and $\boldsymbol{\sigma} \equiv\left(\begin{array}{cc}\boldsymbol{\sigma}_{H} & \boldsymbol{\sigma}_{F}\end{array}\right) \equiv\left(\begin{array}{cc}\sigma_{H 1} & \sigma_{F 1} \\ & \\ \sigma_{H 2} & \sigma_{F 2}\end{array}\right)$.

Because of (2), the difference between the investor-specific after-tax market prices of risk is given by:

$$
\boldsymbol{\theta}_{(2,1)}-\boldsymbol{\theta}_{F}=\left(\boldsymbol{\sigma}^{\mathbf{T}}\right)^{-1}\left[\boldsymbol{\mu}_{H}-\boldsymbol{\mu}_{F}\right]=\left(\boldsymbol{\sigma}^{\mathbf{T}}\right)^{-1}\left[\begin{array}{c}
\mu_{H}-\mu_{H}^{F} \\
\mu_{F}^{H}-\mu_{F}
\end{array}\right]=\left(\boldsymbol{\sigma}^{\mathbf{T}}\right)^{-1}\left[\begin{array}{c}
\tau_{H} \frac{D_{H}}{S_{H}} \\
-\tau_{F} \frac{D_{F}}{S_{F}}
\end{array}\right]
$$

\footnotetext{
${ }^{9}$ We assume that for $\tau$ low enough, the presence of no-short sale constraints does not affect our analysis.

${ }^{10}$ If we define $\varsigma_{i}(t)=\exp \left[-\int_{0}^{t} \boldsymbol{\theta}_{i}^{\prime}(s) d W_{s}-\frac{1}{2} \int_{0}^{t} \boldsymbol{\theta}_{i}(s) \cdot \boldsymbol{\theta}_{i}(s) d s\right]$, we have $\xi_{i}(t)=\frac{\varsigma_{i}(t)}{B(t)}$.
} 


\subsection{Individual consumption-portfolio choice problem}

Investor $i$ is endowed with an initial share $\alpha_{i j}^{0}$ of stock $j$ and with a tax redistribution process $e_{i}$ from the government in units of consumption good. We suppose that each investor receives the taxes paid by the other investor :

$$
e_{H}=\tau_{H} \alpha_{F H} D_{H} \quad e_{F}=\tau_{F} \alpha_{H F} D_{F} .
$$

Taking prices and the tax redistribution process as given, investor $i$ chooses a consumption process $c_{i}$ and a portfolio process $\boldsymbol{\alpha}_{i}=\left(\alpha_{i H}, \alpha_{i F}\right)$ in number of stocks shares. For a policy $\left(c_{i}, \boldsymbol{\alpha}_{i}\right)$ to be admissible, it must be such that the associated financial wealth $X_{i}$, which follows

$$
d X_{i}=X_{i} r d t+\left(e_{i}-c_{i}\right) d t+\underset{(1,2)(2,2)}{\boldsymbol{\alpha}_{i}^{T}} \underset{(2,1)}{\mathbf{I}_{S}}\left[\left(\boldsymbol{\mu}_{i}-\mathbf{r}\right) d t+\underset{(2,2)(2,1)}{\boldsymbol{\sigma}^{T}} d W\right]
$$

satisfies the standard transversality condition (with $\mathbf{I}_{S}$ a diagonal matrix that has $S_{H}$ and $S_{F}$ as coefficients).

The problem facing each investor is to maximize his expected utility over all admissible policies. Since Cox and Huang [1989], it has been well known that this dynamic problem can be transformed into a static variational problem through the use of the underlying state-price density. Hence, each investor's problem can be stated equivalently as follows:

$$
\begin{gathered}
\max _{c_{i}} E\left[\int_{0}^{+\infty} e^{-\rho t} \log \left(c_{i t}\right) d t\right] \\
E\left[\int_{0}^{+\infty} \xi_{i}(t) c_{i}(t) d t\right] \leq \underset{\substack{(1,2) \\
(2,1)}}{\xi_{i}(0) \underset{\left(\boldsymbol{\alpha}_{i}^{0}\right)^{T}}{\mathbf{S}(0)}+E\left[\int_{0}^{+\infty} \xi_{i}(t) e_{i}(t) d t\right] \quad i=H, F}
\end{gathered}
$$

In this formulation, each individual directly chooses his contingent consumption plans under a unique budget constraint featuring state prices. The first-order condition of this problem is:

$$
e^{-\rho t} \frac{1}{c_{i}(t)}=\Psi_{i} \xi_{i}(t) \quad \forall t
$$

where $\Psi_{i}$, the Lagrange multiplier on the budget constraint, is such that

$$
E\left[\int_{0}^{+\infty} \xi_{i}(t) \frac{e^{-\rho t}}{\Psi_{i} \xi_{i}(t)} d t\right]=\xi_{i}(0)\left(\boldsymbol{\alpha}_{i}^{0}\right)^{T} \mathbf{S}(0)+E\left[\int_{0}^{+\infty} \xi_{i}(t) e_{i}(t) d t\right]
$$




\subsection{Equilibrium and optimality}

Given preferences, initial endowments and our tax reallocation rule, an equilibrium is an admissible price system in the sense of section 2.2 and two admissible individual policies $\left(c_{i}, \boldsymbol{\alpha}_{i}\right)$ such that each policy is a solution of the corresponding investor's optimization problem, and all markets clear at all dates, i.e. for all $t \geq 0$ :

- market for good

$$
c_{H}(t)+c_{F}(t)=D_{H}(t)+D_{F}(t)=D(t)
$$

- equity markets

$$
\boldsymbol{\alpha}_{H}(t)+\boldsymbol{\alpha}_{F}(t)=\underset{(2,1)}{\mathbf{1}}
$$

- aggregate demand for the riskless bond is zero, a condition which (given market clearing on equity markets) we can rewrite:

$$
X_{H}(t)+X_{F}(t)=S_{H}(t)+S_{F}(t) .
$$

At equilibrium, the ratio of investors marginal utilities is not constant. Indeed, it is immediate from (4) that

$$
\frac{c_{F}(t)}{c_{H}(t)}=\frac{\Psi_{H} \xi_{H}(t)}{\Psi_{F} \xi_{F}(t)}
$$

Were taxes absent, the two investors would face the same state prices, and their consumption share would be constant, a case of perfect risk-sharing. But because of taxes, the two investors do not face the same state prices and the ratio $\xi_{H} / \xi_{F}$ is not constant, making the ratio of investors marginal utilities stochastic. In other words, because of differential taxation the equilibrium allocation is not Pareto-optimal: the distortion induced by taxes implies a deviation from the first-best allocation. In this context, it will be useful to introduce a stochastic Pareto-Negishi weight - in the spirit of Cuoco and He $[1994]^{11}$. This stochastic weight, noted $\lambda(t)$, plays a key role in the following proposition.

Proposition 1: if an equilibrium $\left(c_{H}^{*}, c_{F}^{*}\right)$ exists, there exists a process $\lambda$ such that

- consumption allocations are given by

$$
c_{H}^{*}(t)=\frac{1}{1+\lambda(t)} D(t) \quad c_{F}^{*}(t)=\frac{\lambda(t)}{1+\lambda(t)} D(t)
$$

\footnotetext{
11 Cuoco and He introduced a representative agent with state dependent utility in an incomplete market setting. Our problem is simpler that theirs in this respect, since we do not have to solve for each investor's minimax state-price density.
} 
- stock prices are

$$
\begin{aligned}
& S_{H}(t)=\frac{D(t)}{1+\lambda(t)} E_{t}\left[\int_{t}^{+\infty} e^{-\rho(s-t)}[1+\lambda(s)] \frac{D_{H}(s)}{D(s)} d s\right] \\
& S_{F}(t)=\frac{\lambda(t) D(t)}{1+\lambda(t)} E_{t}\left[\int_{t}^{+\infty} e^{-\rho(s-t)} \frac{1+\lambda(s)}{\lambda(s)} \frac{D_{F}(s)}{D(s)} d s\right]
\end{aligned}
$$

Besides, the dynamic of $\lambda$ verifies:

$$
\begin{aligned}
\frac{d \lambda}{\lambda} & =\left(\boldsymbol{\theta}_{F}-\boldsymbol{\theta}_{H}\right)^{T}\left[\boldsymbol{\theta}_{F} d t+d \mathbf{W}\right] \\
& \left.=\left[\begin{array}{ll}
-\tau_{H} \frac{D_{H}}{S_{H}} & \tau_{F} \frac{D_{F}}{S_{F}}
\end{array}\right] \underset{(2,2)(2,1)}{\boldsymbol{\sigma}^{-1} \boldsymbol{\theta}_{F} d t+\left[-\tau_{H} \frac{D_{H}}{S_{H}}\right.} \quad \tau_{F} \frac{D_{F}}{S_{F}}\right] \boldsymbol{\sigma}_{(2,2)(2,1)}^{-1} d \mathbf{W}
\end{aligned}
$$

with $\lambda(0)$ such that each investor's constraint is respected. We only need to write one budget constraint, e.g.

$$
\frac{1}{\rho}=E_{0} \int_{0}^{+\infty} e^{-\rho s}\left[\alpha_{H H}^{0}(1+\lambda(s)) \frac{D_{H}(s)}{D(s)}+\lambda(0) \alpha_{H F}^{0} \frac{1+\lambda(s)}{\lambda(s)} \frac{D_{F}(s)}{D(s)}+(1+\lambda(s)) \frac{e_{H}(s)}{D(s)}\right] d s
$$

Proposition 1 states that the equilibrium is entirely characterized by the evolution of one variable which determines the weight of each agent in consumption allocation. At time $t, \lambda(t)$ represents the ratio of consumption $c_{F}(t) / c_{H}(t)$. The higher $\lambda$ the higher the share of total endowment $D$ going to country $F$. The initial value of $\lambda, \lambda(0)$, is determined by the relative wealth of each country in expected present value. Then the evolution of $\lambda$ depends on the evolution of the relative wealth, which itself depends on asset prices dynamics and differences of portfolio composition from one country to the other. Once $\lambda$ is plugged in the pricing kernel, asset prices can be expressed like in (5). $\lambda$ will turn out to be an important state variable. Indeed, when $\lambda$ tends to infinity (respectively to 0 ), prices tend to those that would prevail were there only foreign (resp. home) investors.

Converse of proposition 1: for $\lambda(t)$ a given stochastic process, define stock price processes and consumption allocations as in the previous proposition. If dynamics of $\lambda$ are coherent with (7) and if the budget constraint (8) holds, then $\lambda$ supports an equilibrium.

\subsection{Some equilibrium relationships}

In this section, we give necessary conditions that must hold at equilibrium. These enable us to express some key equilibrium variables, such as expected excess returns or the riskless rate, as functions of other 
endogenous variables, such as price-dividend yields, the asset prices diffusion coefficients, or the coefficient governing the evolution of the consumption ratio $(\lambda)$.

\subsubsection{Expected excess returns}

In order to derive the implications of differential taxation for expected excess returns, we first need to derive investor-specific market prices of risk.

Lemma 1: The after-tax market prices of risk, as perceived by home and foreign investors, are respectively given by

$$
\begin{gathered}
\boldsymbol{\theta}_{H}=\boldsymbol{\sigma}_{D}+\frac{\lambda(t)}{1+\lambda(t)}\left(\boldsymbol{\sigma}^{\mathbf{T}}\right)^{-1}\left(\begin{array}{c}
\tau_{H} \frac{D_{H}}{S_{H}} \\
-\tau_{F} \frac{D_{F}}{S_{F}}
\end{array}\right) \\
\boldsymbol{\theta}_{F}=\boldsymbol{\sigma}_{D}-\frac{1}{1+\lambda(t)}\left(\boldsymbol{\sigma}^{\mathbf{T}}\right)^{-1}\left(\begin{array}{c}
\tau_{H} \frac{D_{H}}{S_{H}} \\
-\tau_{F} \frac{D_{F}}{S_{F}}
\end{array}\right)
\end{gathered}
$$

Using the result of lemma 1 and the definition of $\boldsymbol{\theta}_{i}$ (such that $\boldsymbol{\mu}_{i}-\mathbf{r}=\boldsymbol{\sigma}^{\mathbf{T}} \boldsymbol{\theta}_{i}$ ), proposition 2 characterizing excess returns immediately follows.

Proposition 2: the after-tax expected excess returns, respectively for investors in country $\mathrm{H}$ and in country F, are given by:

$$
\begin{gathered}
\boldsymbol{\mu}_{H}-\mathbf{r}=\boldsymbol{\sigma}^{\mathbf{T}} \boldsymbol{\sigma}_{D}+\frac{\lambda(t)}{1+\lambda(t)}\left(\begin{array}{c}
\tau_{H} \frac{D_{H}}{S_{H}} \\
-\tau_{F} \frac{D_{F}}{S_{F}}
\end{array}\right) \\
\boldsymbol{\mu}_{F}-\mathbf{r}=\boldsymbol{\sigma}^{\mathbf{T}} \boldsymbol{\sigma}_{D}-\frac{1}{1+\lambda(t)}\left(\begin{array}{c}
\tau_{H} \frac{D_{H}}{S_{H}} \\
-\tau_{F} \frac{D_{F}}{S_{F}}
\end{array}\right)
\end{gathered}
$$

Proposition 2 is a modified version of the continuous-time consumption-based CAPM. With logarithmic utility, in the benchmark case without taxes, we would get the vector of expected excess returns for the two assets given by $\boldsymbol{\sigma}^{\mathbf{T}} \boldsymbol{\sigma}_{D}$ : the risk premia are equal to the covariance of asset returns with aggregate consumption growth. The presence of taxes obviously lowers the after-tax risk premium on foreign assets for domestic investors. The before-tax risk premia are given by the upper element of $\boldsymbol{\mu}_{H}-\mathbf{r}$ and by the lower element of $\boldsymbol{\mu}_{F}-\mathbf{r}$. Both are above their level in the benchmark case without taxes. This is because both assets are partly held by taxed investors who require a higher pre-tax excess return to compensate for taxation. The terms in $\tau$ that appear in proposition 2 are interacted with dividend 
yields. This suggests a potential way of testing our international version of the CCAPM, by testing for the significance of this term in the pricing equation.

\subsubsection{Portfolio shares}

Portfolio shares are given by :

$$
\begin{aligned}
& {\left[\begin{array}{c}
\frac{S_{H} \alpha_{H H}}{X_{H}} \\
\frac{S_{F} \alpha_{H F}}{X_{H}}
\end{array}\right]=\boldsymbol{\sigma}^{-1} \boldsymbol{\theta}_{H}+\boldsymbol{\epsilon}_{H}=\boldsymbol{\sigma}^{-1} \boldsymbol{\sigma}_{D}+\frac{\lambda(t)}{1+\lambda(t)}\left(\boldsymbol{\sigma}^{\mathbf{T}} \boldsymbol{\sigma}\right)^{-1}\left(\begin{array}{c}
\tau_{H} \frac{D_{H}}{S_{H}} \\
-\tau_{F} \frac{D_{F}}{S_{F}}
\end{array}\right)+\boldsymbol{\epsilon}_{H}} \\
& {\left[\begin{array}{c}
\frac{S_{H} \alpha_{F H}}{X_{F}} \\
\frac{S_{F} \alpha_{F F}}{X_{F}}
\end{array}\right]=\boldsymbol{\sigma}^{-1} \boldsymbol{\theta}_{F}+\boldsymbol{\epsilon}_{F}=\boldsymbol{\sigma}^{-1} \boldsymbol{\sigma}_{D}-\frac{1}{1+\lambda(t)}\left(\boldsymbol{\sigma}^{\mathbf{T}} \boldsymbol{\sigma}\right)^{-1}\left(\begin{array}{c}
\tau_{H} \frac{D_{H}}{S_{H}} \\
-\tau_{F} \frac{D_{F}}{S_{F}}
\end{array}\right)+\boldsymbol{\epsilon}_{F}}
\end{aligned}
$$

On each line, the first term $\boldsymbol{\sigma}^{-1} \boldsymbol{\theta}_{i}=\left(\boldsymbol{\sigma}^{\mathrm{T}} \boldsymbol{\sigma}\right)^{-1}\left[\boldsymbol{\mu}_{i}-\mathbf{r}\right]$ is the standard portfolio composition of a logarithmic investor in complete markets. We see that for an investor in country $H, \tau_{F}$ reduces the demand for foreign stocks by reducing after-tax expected returns on these stocks. Symmetrically, due to market clearing, $\tau_{H}$ increases the domestic demand for domestic shares.

The second term $\boldsymbol{\epsilon}_{i}$ comes from the redistribution of taxes: for instance, since taxes redistributed to investor $H$ are proportionnal to $D_{H}$, this will create a demand for foreign shares in order to hedge this additionnal risk on domestic output, which shows up in $\boldsymbol{\epsilon}_{H}$. However, we do not want to insist on this additionnal term since it will be quantitatively small under reasonable assumptions ${ }^{12}$.

\subsubsection{The riskless rate}

\section{Proposition 3:}

$$
\begin{aligned}
& r=\rho+\mu_{D}-\boldsymbol{\sigma}_{D} \cdot \boldsymbol{\sigma}_{D}-\frac{\lambda}{(1+\lambda)^{2}} \boldsymbol{\sigma}_{\lambda} \cdot \boldsymbol{\sigma}_{\lambda} \\
& =\rho+\mu_{D}-\boldsymbol{\sigma}_{D} \cdot \boldsymbol{\sigma}_{D}-\frac{\lambda}{(1+\lambda)^{2}}\left[\begin{array}{ll}
\tau_{H} \frac{D_{H}}{S_{H}} & -\tau_{F} \frac{D_{F}}{S_{F}}
\end{array}\right]\left(\boldsymbol{\sigma}^{T} \boldsymbol{\sigma}\right)^{-1}\left[\begin{array}{c}
\tau_{H} \frac{D_{H}}{S_{H}} \\
-\tau_{F} \frac{D_{F}}{S_{F}}
\end{array}\right]
\end{aligned}
$$

where $\boldsymbol{\sigma}_{D} \cdot \boldsymbol{\sigma}_{D} \equiv \boldsymbol{\sigma}_{D}^{T} \boldsymbol{\sigma}_{D}$. In the fully integrated case $(\tau=0)$, we get the standard interest rate formula: with logarithmic utility, when perfect risk-sharing prevails, the interest rate is determined by the rate of time preference, the average growth rate of aggregate consumption and its volatility. Once the endogenous

\footnotetext{
12 The way taxes are redistributed is a bit arbitrary anyway. It can be proved that there exists a redistribution scheme such that $\epsilon_{H}=0$.
} 
variables are determined (in section 3), we will be able to see how exactly the riskless rate is affected by an increase in $\tau$. For now, since $\left(\boldsymbol{\sigma}^{T} \boldsymbol{\sigma}\right)^{-1}$ is definite positive, we can just say that the interest rate is below its level of perfect integration. This is to be interpreted as an effect of higher savings for precautionary motive, due to the fact that because of taxes investors hold less diversified portfolios and have greature exposure to their domestic risk.

\subsection{Complete characterization of a markovian equilibrium}

Assuming that there exists a markovian equilibrium, i.e. an equilibrium with $(D, \delta, \lambda)$ jointly markov, we will now characterize it and show how to construct it.

Lemma 2: we can write

$$
\begin{aligned}
& S_{H}(t)=S_{H}(D(t), \delta(t), \lambda(t))=\frac{D(t)}{1+\lambda(t)} h(\delta(t), \lambda(t)) \\
& S_{F}(t)=S_{F}(D(t), \delta(t), \lambda(t))=\frac{\lambda(t) D(t)}{1+\lambda(t)} f(\delta(t), \lambda(t))
\end{aligned}
$$

with

$$
\begin{gathered}
h(\delta(t), \lambda(t)) \equiv E\left[\int_{t}^{+\infty} e^{-\rho(s-t)}[1+\lambda(s)] \delta(s) d s \mid \delta(t), \lambda(t)\right] \\
f(\delta(t), \lambda(t)) \equiv E\left[\int_{t}^{+\infty} e^{-\rho(s-t)} \frac{1+\lambda(s)}{\lambda(s)}(1-\delta(s)) d s \mid \delta(t), \lambda(t)\right]
\end{gathered}
$$

Proof: on each line, the first equality follows from the markov assumption and the second equality follows from the stock prices formulas in proposition 1 and from the definition of functions $h$ and $f$.

Proposition 4: the functions $h$ and $f$ are solutions of the following PDEs

$$
\begin{gathered}
\rho h=(1+\lambda) \delta+\delta \mu_{\delta} h_{\delta}+\lambda \mu_{\lambda} h_{\lambda}+\frac{1}{2} \delta^{2}\left(\boldsymbol{\sigma}_{\delta} \cdot \boldsymbol{\sigma}_{\delta}\right) h_{\delta \delta}+\frac{1}{2} \lambda^{2}\left(\boldsymbol{\sigma}_{\lambda} . \boldsymbol{\sigma}_{\lambda}\right) h_{\lambda \lambda}+\delta \lambda\left(\boldsymbol{\sigma}_{\delta} \cdot \boldsymbol{\sigma}_{\lambda}\right) h_{\delta \lambda} \\
\rho f=\frac{1+\lambda}{\lambda}(1-\delta)+\delta \mu_{\delta} f_{\delta}+\lambda \mu_{\lambda} f_{\lambda}+\frac{1}{2} \delta^{2}\left(\boldsymbol{\sigma}_{\delta} \cdot \boldsymbol{\sigma}_{\delta}\right) f_{\delta \delta}+\frac{1}{2} \lambda^{2}\left(\boldsymbol{\sigma}_{\lambda} . \boldsymbol{\sigma}_{\lambda}\right) f_{\lambda \lambda}+\delta \lambda\left(\boldsymbol{\sigma}_{\delta} . \boldsymbol{\sigma}_{\lambda}\right) f_{\delta \lambda}
\end{gathered}
$$

with :

$$
\begin{aligned}
\mu_{\delta} & \equiv(1-\delta)\left[\mu_{D_{H}}-\mu_{D_{F}}-\delta \boldsymbol{\sigma}_{D_{H}}^{T} \boldsymbol{\sigma}_{D_{H}}+(1-\delta) \boldsymbol{\sigma}_{D_{F}}^{T} \boldsymbol{\sigma}_{D_{F}}+(2 \delta-1) \boldsymbol{\sigma}_{D_{H}}^{T} \boldsymbol{\sigma}_{D_{F}}\right] \\
\boldsymbol{\sigma}_{\delta} & \equiv(1-\delta)\left(\boldsymbol{\sigma}_{D_{H}}-\boldsymbol{\sigma}_{D_{F}}\right)
\end{aligned}
$$

so that $d \delta=\delta \mu_{\delta} d t+\delta \boldsymbol{\sigma}_{\delta}^{T} d \mathbf{W}$ and 


$$
\begin{aligned}
& \mu_{\lambda} \equiv\left[-\tau_{H} \frac{D_{H}}{S_{H}} \quad \tau_{F} \frac{D_{F}}{S_{F}}\right] \boldsymbol{\sigma}^{-1} \boldsymbol{\sigma}_{D}+\frac{1}{1+\lambda(t)}\left[-\tau_{H} \frac{D_{H}}{S_{H}} \quad \tau_{F} \frac{D_{F}}{S_{F}}\right]\left(\boldsymbol{\sigma}^{\mathbf{T}} \boldsymbol{\sigma}\right)^{-1}\left(\begin{array}{c}
-\tau_{H} \frac{D_{H}}{S_{H}} \\
\tau_{F} \frac{D_{F}}{S_{F}}
\end{array}\right) \\
& \boldsymbol{\sigma}_{\lambda} \equiv\left(\boldsymbol{\sigma}^{\mathbf{T}}\right)^{-1}\left(\begin{array}{c}
-\tau_{H} \frac{D_{H}}{S_{H}} \\
\tau_{F} \frac{D_{F}}{S_{F}}
\end{array}\right) \text {, so that } d \lambda=\lambda \mu_{\lambda} d t+\lambda \boldsymbol{\sigma}_{\lambda}^{T} d W
\end{aligned}
$$

Proof: Apply the Feynmac-Kac formula to $h$ and $f$ to get the PDEs and apply Ito's lemma to $\delta$ to derive $\mu_{\delta}$ and $\boldsymbol{\sigma}_{\delta}$.

Besides, the diffusion matrix for stock prices $\boldsymbol{\sigma}$ has to be coherent with functions $h$ and $f$. This is what the following proposition states.

Proposition 5 (restriction on $\boldsymbol{\sigma}_{H}$ and $\left.\boldsymbol{\sigma}_{F}\right)$ :

$$
\begin{gathered}
h \boldsymbol{\sigma}_{H}=h \boldsymbol{\sigma}_{D}+\lambda\left(h_{\lambda}-\frac{h}{1+\lambda}\right) \boldsymbol{\sigma}_{\lambda}+\delta h_{\delta} \boldsymbol{\sigma}_{\delta} \\
f \boldsymbol{\sigma}_{F}=f \boldsymbol{\sigma}_{D}+\lambda\left(f_{\lambda}+\frac{f}{\lambda(1+\lambda)}\right) \boldsymbol{\sigma}_{\lambda}+\delta f_{\delta} \boldsymbol{\sigma}_{\delta}
\end{gathered}
$$

In order to solve for equilibrium for any $\tau$, we would have to solve a quadratic equation in $\boldsymbol{\sigma}$ (based on equations (11) and (12)) and express its four coefficients as functions of $h, f$ and their partial derivatives. Then we would able to reexpress $\mu_{\lambda}$ and $\boldsymbol{\sigma}_{\lambda}$ in (9) and (10) and get a non linear system of PDEs in $h$ and $f$. But even numerically, we doubt that the solution of this system would be easily tractable. In order to save on computational difficulties and also to preserve closed-form expressions, we will rather consider the case where $\tau_{H}=\tau_{F}=\tau$ is close to zero. This will enable us to give an approximation of equilibrium in the neighborhood of the case of perfect integration by solving simple ODEs.

\section{Results}

Cochrane, Longstaff and Santa-Clara [2003] have completely solved for equilibrium in the case with no dividend taxation, with closed-form solutions for asset prices. They give two functions $y_{H}$ and $y_{F}$ (reproduced in the appendix) such that

$$
\begin{aligned}
& S_{H}(t)=S_{H}(D(t), \delta(t))=D(t) y_{H}(\delta(t)) \\
& S_{F}(t)=S_{F}(D(t), \delta(t))=D(t) y_{F}(\delta(t))
\end{aligned}
$$


In what follows, we derive Taylor expansions around this case of perfect risk-sharing and give approximate closed-form expressions for asset prices, returns joint dynamics and equity portfolios for $\tau_{H}=\tau_{F}=\tau$ close to zero. All symbols with subscript 0 will refer to the case studied in Cochrane et al. where $\tau=0$.

\subsection{Asset prices}

Proposition 6: To a first order, $S_{H}$ and $S_{F}$ are given by :

$$
\begin{aligned}
& S_{H}\left(D_{t}, \delta_{t}, \lambda_{t} ; \tau\right)=D_{t}\left[1-\tau \frac{\lambda_{t}}{1+\lambda_{t}}\right] y_{H}\left(\delta_{t}\right)+o(\tau) \\
& S_{F}\left(D_{t}, \delta_{t}, \lambda_{t} ; \tau\right)=D_{t}\left[1-\tau \frac{1}{1+\lambda_{t}}\right] y_{F}\left(\delta_{t}\right)+o(\tau)
\end{aligned}
$$

The first-order effect of imperfect market integration is to reduce equilibrium asset prices: frictions on financial markets translate into lower prices by reducing expecting income streams on domestic shares received by foreigners. Note that the decrease in domestic asset prices is higher when $\lambda$ is higher: this makes sense since $\lambda$ measures the relative influence of foreign investors in the pricing of assets (the higher $\lambda$ the richer the foreign investors relative to the domestic ones). The relative wealth of both countries matters for asset prices: when countries are similar in other respects, asset prices of country $H$ are lower if country $H$ is the poorest $(\lambda>1)$ since foreigners have a higher influence in the pricing of assets and they are willing to pay a lower price.

Proposition 7: To a second order, $S_{H}$ and $S_{F}$ are given by

$$
\begin{aligned}
& S_{H}(t)=D_{t}\left[y_{H}(\delta)\left(1-\tau \frac{\lambda}{1+\lambda}+\tau^{2} \frac{\lambda}{(1+\lambda)^{2}}\right)+\tau^{2} \frac{\lambda}{(1+\lambda)^{2}} h_{2}(\delta)\right]+o\left(\tau^{2}\right) \\
& S_{F}(t)=D_{t}\left[y_{F}(\delta)\left(1-\tau \frac{1}{1+\lambda_{t}}+\tau^{2} \frac{\lambda}{(1+\lambda)^{2}}\right)+\tau^{2} \frac{\lambda}{(1+\lambda)^{2}} f_{2}(\delta)\right]+o\left(\tau^{2}\right)
\end{aligned}
$$

where $h_{2}(\delta)$ and $f_{2}(\delta)$ are solutions of the following ODE

$$
\begin{aligned}
\rho h_{2}-\delta \mu_{\delta} h_{2}^{\prime}-\frac{1}{2} \delta^{2} \boldsymbol{\sigma}_{\delta}^{T} \boldsymbol{\sigma}_{\delta} h_{2}^{\prime \prime} & =\left(\boldsymbol{\Omega}_{0} \cdot \boldsymbol{\Omega}_{0}\right) y_{H} \\
\rho f_{2}-\delta \mu_{\delta} f_{2}^{\prime}-\frac{1}{2} \delta^{2}\left(\boldsymbol{\sigma}_{\delta}^{T} \boldsymbol{\sigma}_{\delta}\right) f_{2}^{\prime \prime} & =\left(\boldsymbol{\Omega}_{0} \boldsymbol{\Omega}_{0}\right) y_{F}
\end{aligned}
$$

with boundary conditions :

$$
\begin{gathered}
\left\{\begin{array}{c}
h_{2}(0)=0 \\
h_{2}(1)=\frac{1}{\rho^{2}} \boldsymbol{\Omega}_{0}(1) \cdot \boldsymbol{\Omega}_{0}(1)
\end{array}\right. \\
\left\{\begin{array}{c}
f_{2}(0)=\frac{1}{\rho^{2}} \boldsymbol{\Omega}_{0}(0) \cdot \boldsymbol{\Omega}_{0}(0) \\
f_{2}(1)=0
\end{array}\right.
\end{gathered}
$$


and

$$
\boldsymbol{\Omega}_{0}(\delta) \equiv\left(\boldsymbol{\sigma}_{0}^{T}\right)^{-1}\left[\begin{array}{c}
-\left(\frac{D_{H}}{S_{H}}\right)_{0} \\
\left(\frac{D_{F}}{S_{F}}\right)_{0}
\end{array}\right]
$$

Making sense of the second order price effects of integration requires to understand its impacts on the riskless rate and on the variance-covariance matrix of returns. We will see below that to a second order, the riskless rate and the return correlation decrease, both effects having a positive impact on asset prices through the risk-adjusted discount factor.

\subsection{Instantaneous volatility and correlation}

Using $h_{2}$ and $f_{2}$ solutions of the ODEs above, we get the second-order expansion of $\boldsymbol{\sigma}_{H}$ and $\boldsymbol{\sigma}_{F}$. A conspicuous feature of these expressions is the absence of first order impact of taxes on returns secondorder moments.

\section{Proposition 8:}

$$
\begin{aligned}
& \boldsymbol{\sigma}_{H}=\boldsymbol{\sigma}_{H 0}+\tau^{2} \frac{\lambda}{(1+\lambda)^{2}}\left\{-\boldsymbol{\Omega}_{0}+\left[\frac{h_{2}^{\prime}}{y_{H}}-\lambda \frac{y_{H}^{\prime}}{y_{H}}-\frac{h_{2} y_{H}^{\prime}}{\left(y_{H}\right)^{2}}\right] \delta \boldsymbol{\sigma}_{\delta}\right\}+o\left(\tau^{2}\right) \\
& \boldsymbol{\sigma}_{F}=\boldsymbol{\sigma}_{F 0}+\tau^{2} \frac{\lambda}{(1+\lambda)^{2}}\left\{\boldsymbol{\Omega}_{0}+\left[\frac{f_{2}^{\prime}}{y_{F}}-\frac{1}{\lambda} \frac{y_{F}^{\prime}}{y_{F}}-\frac{f_{2} y_{F}^{\prime}}{\left(y_{F}\right)^{2}}\right] \delta \boldsymbol{\sigma}_{\delta}\right\}+o\left(\tau^{2}\right)
\end{aligned}
$$

Before illustrating these formulas, we will briefly describe our baseline calibration choice. We take the following parameters: $\rho=0.04, \mu_{D_{H}}=\mu_{D_{F}}=0.025, \sigma_{D_{H}, 1}=0.145, \sigma_{D_{H}, 2}=0.039, \sigma_{D_{F}, 1}=0.039$ and $\sigma_{D_{F}, 2}=0.145^{13}$. This calibration matches the US stock market data: on an annual basis, the S\&P500 volatility after World War II is 0.15 and the dividend yield is around 0.04 (and is equal to $\rho$ is the symmetric case of perfect integration). Our fundamental correlation $\eta$ is equal to 0.5 , which is consistent with the empirical stock returns correlation of 0.58 between the US and a non-US synthetic world index over the period $1980-2000^{14} . \tau$ is a free parameter the impact of which we are interested in. Gordon and Hines [2002] provide some useful information on international taxation. First, domestic investors pay withholding taxes when repatriating foreign dividends. These taxes depend on the foreign countries considered but are typically around $10 \%^{15}$. Second, investors can claim tax rebate on domestic

\footnotetext{
13 This corresponds to $\sigma_{D}=0.15$ and to a fundamental correlation $\eta=0.5$. This calibration allow us to match the moments of stock returns in the US at the expense of the moments observed for the fundamentals. It is well known that the volatility of stock markets is much higher than the volatility of GDP.

14 The empirical stock returns correlation is calculated using monthly returns of both indexes in US\$.

15 Investors can claim foreign tax credits in some countries but anyway those credits are subject to ceiling limits and do not apply to tax-exempt investment plans (like retirement plans).
} 
investment to avoid the double-taxation of profits (since profits are already subject to the corporate tax) whereas such tax rebate is not available on foreign assets, driving a wedge in the taxation of both assets. At the bottom line, it seems that reasonable values for $\tau$ are between $10 \%$ and $15 \%^{16}$.

Figure 1 below illustrates the impact of $\tau$ on asset volatility in a perfectly symmetric case. From (13) and (14), we can also compute the instantaneous correlation between returns and see how it is affected by $\tau$. As shown in figure 2, we find that the correlation monotonously decreases with $\tau$. To understand the impact of the degree of market integration on the equilibrium correlation of returns, we can first consider the case of perfect integration, as opposed to the case of full segmentation. When markets are fully segmented, a good shock on the dividends of an asset in one country has no impact on the price of assets in another country. But it is different when investors can hold assets everywhere without any obstacle. The reason is that following the rise in the domestic price due to the good domestic shock, the share of asset $H$ in the "world market portfolio" automatically increases, making country $F$ asset more appealling because the diversification opportunities it offers are suddenly more cherished. The required excess return on asset $F$ decreases and its price increases to restore equilibrium on the asset market ${ }^{17}$. When $\tau>0$, the same sort of mechanism is at work but attenuated due to investors heterogeneity. Indeed, a good $D_{H}$ affects differently both investors (who share risk imperfectly): the home investor is the most affected since his portfolio is biased towards home assets - and he is reluctant to rebalance his portfolio towards foreign assets. This attenuates the increase in $S_{F}$ compared to the case of perfect risk-sharing. Then, when cross-border impediments to foreign equity holdings are relaxed, we should observe a higher level of stock returns correlations between countries: this is consistent with the empirical findings of Bekaert and Harvey [2000] who showed that equity market liberalization increases stock markets comovement of countries with the rest of the world for a sample of emerging economies.

\footnotetext{
${ }^{16}$ For the US, the relevant withholding tax is $15 \%$ with European countries and Japan.

17 And the increase of $S_{H}$ is also lower than under full segmentation. This reasoning holds when the market shares of $H$ is not "too small" to start with.
} 


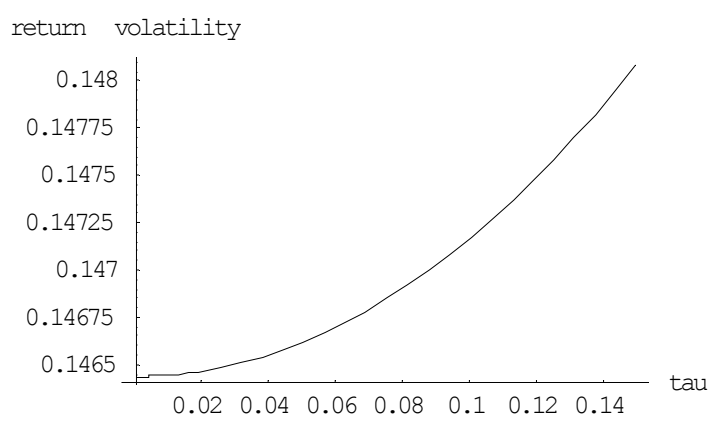

Figure 1: Stock returns volatility in the symmetric case as a function of $\tau$. (Calibration : $\rho=0.04$, $\left.\mu_{D_{H}}=\mu_{D_{F}}=0.025, \sigma_{D_{H}, 1}=\sigma_{D_{F}, 2}=0.145, \sigma_{D_{H}, 2}=\sigma_{D_{F}, 1}=0.039\right)$.

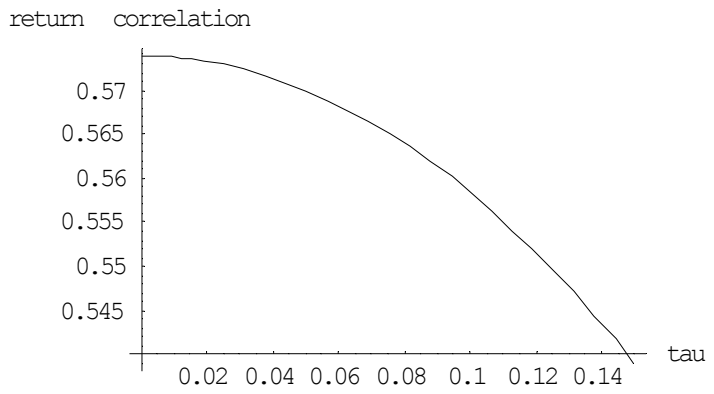

Figure 2: Stock returns correlation in the symmetric case as a function of $\tau$. (Calibration : $\rho=0.04$, $\left.\mu_{D_{H}}=\mu_{D_{F}}=0.025, \sigma_{D_{H}, 1}=\sigma_{D_{F}, 2}=0.145, \sigma_{D_{H}, 2}=\sigma_{D_{F}, 1}=0.039\right)$.

Table 1 shows the magnitude of this effect conditional on three structural parameters: the degree of market integration (inversely related to $\tau$ ), the level of fundamental correlation $\eta$ and the rate of time preference $\rho$. We see that for given $\eta$ and $\rho$, the correlation of asset returns is always monotonously decreasing in $\tau$, consistently with figure 2. It should be noticed that for a higher level of fundamental correlation, the equilibrium correlation of asset returns $\eta_{S}$ is closer to its fundamental value $\eta$, meaning that endogenous comovements of asset prices are less important: when the fundamental correlation is higher, high dividends in one country are often accompanied by high dividends in the other country, reducing the incentives to rebalance the portfolio. Finally, we find that the impact of financial integration on the equilibrium returns correlation is much higher when the rate of time preference is low. The intuition for this effect is not obvious - except for the fact that in the limit case of complete myopia, the optimal portfolio rebalancing behaviour that induces endogenous comovements of asset prices no longer exists. 


\begin{tabular}{|c|c|c|c|c|}
\hline & \multicolumn{3}{|c|}{$\eta_{S}$} \\
\hline & & $\rho=0.1$ & $\rho=0.05$ & $\rho=0.01$ \\
\hline$\eta=0$ & $\begin{array}{l}\tau=0 \\
\tau=5 \% \\
\tau=10 \%\end{array}$ & $\begin{array}{l}0.087 \\
0.080 \\
0.060\end{array}$ & $\begin{array}{l}0.150 \\
0.144 \\
0.131\end{array}$ & $\begin{array}{l}0.394 \\
0.393 \\
0.389\end{array}$ \\
\hline$\eta=0.25$ & $\begin{array}{l}\tau=0 \\
\tau=5 \% \\
\tau=10 \%\end{array}$ & $\begin{array}{l}0.315 \\
0.307 \\
0.284\end{array}$ & $\begin{array}{l}0.360 \\
0.355 \\
0.342\end{array}$ & $\begin{array}{l}0.543 \\
0.541 \\
0.537\end{array}$ \\
\hline$\eta=0.5$ & $\begin{array}{l}\tau=0 \\
\tau=5 \% \\
\tau=10 \%\end{array}$ & $\begin{array}{l}0.539 \\
0.530 \\
0.504\end{array}$ & $\begin{array}{l}0.566 \\
0.560 \\
0.546\end{array}$ & $\begin{array}{l}0.680 \\
0.678 \\
0.674\end{array}$ \\
\hline
\end{tabular}

Table 1 : Stock return correlation $\eta_{S}$ as a function of the fundamental correlation $\eta$ and obstacles to international investment $\tau$ (for a given volatility of fundamentals $\sigma_{D}=0,15$ )

\subsection{Portfolio composition}

To a first order, portfolio shares are given by :

$$
\begin{gathered}
{\left[\begin{array}{c}
\frac{S_{H} \alpha_{H H}}{X_{H}} \\
\frac{S_{F} \alpha_{H F}}{X_{H}}
\end{array}\right]=\boldsymbol{\sigma}_{0}^{-1} \boldsymbol{\sigma}_{D}+\tau \frac{\lambda}{1+\lambda}\left(\boldsymbol{\sigma}_{0}^{T} \boldsymbol{\sigma}_{0}\right)^{-1}\left[\begin{array}{c}
\frac{D_{H}}{S_{H}} \\
-\frac{D_{F}}{S_{F}}
\end{array}\right]+\boldsymbol{\epsilon}_{H}+o(\tau)} \\
{\left[\begin{array}{c}
\frac{S_{H} \alpha_{F H}}{X_{F}} \\
\frac{S_{F} \alpha_{F F}}{X_{F}}
\end{array}\right]=\boldsymbol{\sigma}_{0}^{-1} \boldsymbol{\sigma}_{D}+\tau \frac{1}{1+\lambda}\left(\boldsymbol{\sigma}_{0}^{T} \boldsymbol{\sigma}_{0}\right)^{-1}\left[\begin{array}{c}
-\frac{D_{H}}{S_{H}} \\
\frac{D_{F}}{S_{F}}
\end{array}\right]+\boldsymbol{\epsilon}_{F}+o(\tau)}
\end{gathered}
$$

Proof : Immediate using section 2.5.2 and $\left(\boldsymbol{\sigma}^{T}\right)^{-1}=\left(\boldsymbol{\sigma}_{0}^{T}\right)^{-1}+o(\tau)$.

In the appendix, we show that to a first order $\epsilon_{H}^{T}=\tau \lambda\left(S_{H} S_{F} /\left(S_{H}+S_{F}\right)^{2}\right)[-1 \quad 1]$. The redistribution of taxes generates some "foreign bias" in portfolios since redistributed endowments create an additionnal exposition towards domestic dividends and make foreign assets attractive to hegde that risk. However, since this term is found to be quantitatively small when the two countries are not too asymmetric and since it depends very much on the assumed system of redistribution, we will neglect it from now on but none of the following results rely on this approximation. 
Portfolio shares can easily be interpreted as deviations from the world market portfolio. Introducing the following notations for the elements of the instantaneous variance-covariance matrix for stock prices,

$$
\begin{aligned}
\boldsymbol{\sigma}^{T} \boldsymbol{\sigma}= & \left(\begin{array}{cc}
\sigma_{S_{H}}^{2} & \eta_{S} \sigma_{S_{H}} \sigma_{S_{F}} \\
\eta_{S} \sigma_{S_{H}} \sigma_{S_{F}} & \sigma_{S_{F}}^{2}
\end{array}\right) \text {, we can rewrite (15) and (16) as follows: } \\
& \frac{S_{H} \alpha_{H}}{X_{H}}=\rho y_{H}(\delta)\left(1+\tau \frac{\eta_{S}}{1-\eta_{S}^{2}} \frac{\lambda}{1+\lambda} \frac{1}{\sigma_{S_{H}} \sigma_{S_{F}}} \frac{1}{\Phi_{H}} \frac{D_{F}}{S_{F}}+\frac{\tau}{1-\eta_{S}^{2}} \frac{\lambda}{1+\lambda} \frac{1}{\sigma_{S_{H}}^{2}} \frac{1}{\Phi_{H}} \frac{D_{H}}{S_{H}}\right) \\
& \frac{S_{F} \alpha_{H F}}{X_{H}}=\rho y_{F}(\delta)\left(1-\frac{\tau}{1-\eta_{S}^{2}} \frac{\lambda}{1+\lambda} \frac{1}{\sigma_{S_{F}}^{2}} \frac{1}{\Phi_{F}} \frac{D_{F}}{S_{F}}-\tau \frac{\eta_{S}}{1-\eta_{S}^{2}} \frac{\lambda}{1+\lambda} \frac{1}{\sigma_{S_{H}} \sigma_{S_{F}}} \frac{1}{\Phi_{F}} \frac{D_{H}}{S_{H}}\right)
\end{aligned}
$$

where $\Phi_{j} \equiv \frac{S_{j}}{S_{H}+S_{F}}$. When $\tau=0, \frac{S_{H} \alpha_{H H}}{X_{H}}$ (resp. $\frac{S_{F} \alpha_{H F}}{X_{H}}$ ) is simply $\rho y_{H}(\delta)$, which is equal to $\frac{S_{H}}{S_{H}+S_{F}}$ (resp. $\left.\rho y_{F}(\delta)=\frac{S_{F}}{S_{H}+S_{F}}\right)$ : without frictions in financial markets, since there is no heterogeneity among investors, the portfolio composition of a home investor is exactly the world market portfolio, which contains a share $\frac{S_{H}}{S_{H}+S_{F}}$ of domestic assets (resp. a share $\frac{S_{F}}{S_{H}+S_{F}}$ of foreign assets). The existence of frictions on international financial markets generates deviations from this benchmark case. As already mentionned in section 2.5.2, taxes on foreign assets directly reduce foreign asset holdings of domestic investors and make them rebalance their portfolio towards domestic assets - and symmetrically, as the tax reduces the demand of domestic shares by foreigners, this generates an additionnal bias towards domestic shares for domestic investors (which accounts for the presence of two terms in $\tau$ ). The size of the bias in portfolios is proportional to $\frac{1}{1-\eta_{S}^{2}}$, where $\eta_{S}$ denotes the correlation between assets: when assets are close substitutes (high $\eta_{S}$ ), the effect of the friction on equity holdings is amplified.

\section{Some comparative statics in a simple symmetric case}

In the symmetric case where $\tau_{F}=\tau_{H}=\tau, \sigma_{S_{H}}=\sigma_{S_{F}}=\sigma_{S}, \mu_{D_{H}}=\mu_{D_{F}}$ and $\delta=\frac{1}{2}$, we get :

$$
\frac{E q_{H H}}{X_{H}}=\frac{1}{2}+\tau \frac{\lambda}{1+\lambda} \frac{\rho}{\sigma_{S}^{2}\left(1-\eta_{S}\right)} \quad \frac{E q_{H F}}{X_{H}}=\frac{1}{2}-\tau \frac{\lambda}{1+\lambda} \frac{\rho}{\sigma_{S}^{2}\left(1-\eta_{S}\right)}
$$

where $E q_{i j}$ denotes equity holdings (at market value) of country $i$ in country $j$. Simple comparative statics tell us that when assets are closer substitutes (higher $\eta_{S}$ ), as foreign assets offer less diversification opportunities, foreign asset holdings decrease (and domestic asset holdings increase) $)^{18}$

$$
\frac{\partial E q_{H F}}{\partial \eta_{S}}=-\frac{\partial E q_{H H}}{\partial \eta_{S}}=-\tau \frac{\lambda}{1+\lambda} \frac{\rho}{\sigma_{S}^{2}\left(1-\eta_{S}\right)^{2}} X_{H}<0
$$

and the impact of $\tau$ is magnified: $\frac{\partial E q_{H F}}{\partial \eta_{S}}=-\frac{\lambda}{1+\lambda} \frac{\rho}{\sigma_{S}^{2}\left(1-\eta_{S}\right)} X_{H}<0$ and $\left|\frac{\partial E q_{H F}}{\partial \partial \tau}\right|$ is increasing in $\eta_{S}$.

\footnotetext{
18 Notice that the correlation has no impact on portfolio composition if $\tau=0$.
} 
These effects are shown in figure 3 for $\lambda=1, \rho=0.04$ and $\sigma_{D}=0.15$, for three different values of $\tau(0,8 \%$ and $15 \%)$. We see that under reasonable friction $(\tau=15 \%)$ and reasonable return correlation $\left(\eta_{S}=0.5\right)$, we are able to generate substantial deviations from the world market portfolio (which has an equal share in domestic and foreign assets).

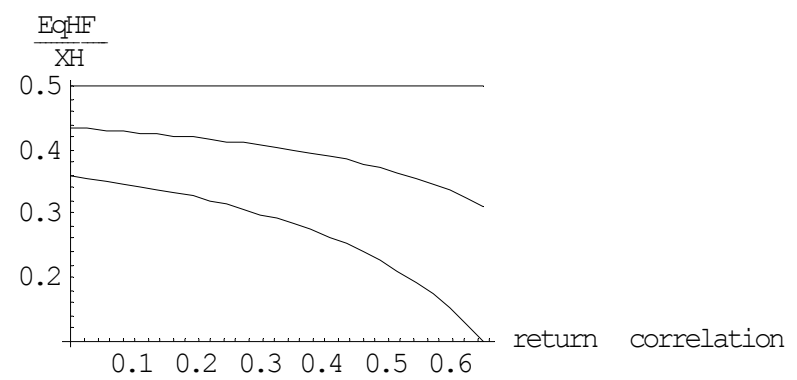

Figure 3: Share of domestic wealth invested abroad in the symmetric case as a function of stock return correlation, for various $\tau$ (Calibration : $\rho=0.04, \mu_{D_{H}}=\mu_{D_{F}}=0.025, \sigma_{H}=\sigma_{F}=0.146$ ).

When investments are riskier (higher $\sigma_{S}$ ), holdings of foreign assets increase as the motive for risksharing increases:

$$
\frac{\partial E q_{H F}}{\partial \sigma_{S}^{2}}=-\frac{\partial E q_{H H}}{\partial \sigma_{S}^{2}}=\tau \frac{\lambda}{1+\lambda} \frac{\rho}{\sigma_{S}^{4}\left(1-\eta_{S}\right)} X_{H}>0
$$

Finally, our model predicts that the "home bias" in portfolios should be larger in countries whose relative wealth (captured by $\lambda$ ) is smaller, a prediction consistent with the evidence in Chan et al. $[2004]^{19}$. The higher $\lambda$, the larger the negative impact of the friction on the price of the domestic asset (because of the increased influence of foreigners in the pricing of the domestic asset) and the larger the incentive for domestic investors to buy their home asset. In the symmetric case, we have :

$$
\frac{\partial E q_{H H}}{\partial \lambda}=-\frac{\partial E q_{H F}}{\partial \lambda}=\tau \frac{1}{(1+\lambda)^{2}} \frac{\rho}{\sigma^{2}\left(1-\eta_{S}\right)^{2}} X_{H}>0
$$

\footnotetext{
19 The lowest three values taken by their measure of home bias (computed as deviation from the world market portfolio) are for the three largest markets (namely US, UK and Japan) and the largest four are for New Zealand, Norway, Portugal and Greece.
} 


\subsection{A gravity equation for bilateral equity holdings}

Our model gives theoretical foundations to gravity equations on bilateral equity holdings. Indeed, when we turn from portfolio shares to the value of equity holdings, we have :

$$
\log \left(E q_{H F}\right) \equiv \log \left(S_{F} \alpha_{H F}\right)=\log X_{H}+\log \left(\rho y_{F}(\delta)\right)-\tau \frac{1}{1-\eta_{S}^{2}} \frac{\lambda}{1+\lambda} \frac{1}{\sigma_{F} \Phi_{F}}\left(\frac{1}{\sigma_{F}} \frac{D_{F}}{S_{F}}+\eta_{S} \frac{1}{\sigma_{H}} \frac{D_{H}}{S_{H}}\right)
$$

where $\log X_{H}$ and $\log \left(\rho y_{F}(\delta)\right)$ are the mass terms in the gravity equation ${ }^{20}$.

As shown by Portes and Rey [2005], gravity equations perform well in describing international asset allocation. In their setup, they use the market capitalizations of origin and destination countries as proxies for the mass terms of the equation. Our model clarifies which variables should be used: for the origin country, one should use the aggregate wealth $\left(X_{H}\right)$ of the country ${ }^{21}$ and market capitalization might be an imperfect proxy of it, whereas for the destination country, the market capitalization is certainly more appropriate as a proxy for the present value of current and future foreign dividend streams $\left(\rho y_{F}(\delta)\right)$. Moreover, Portes and Rey [2005] propose to interact variables of financial frictions between countries with the degree of substituability between assets (measured here by $1 /\left(1-\eta_{S}^{2}\right)$ ). Our model provides theoretical foundations to such a procedure.

\subsection{The riskless rate}

The second-order approximation of the riskless rate is given by :

$$
\begin{aligned}
& r=\rho+\mu_{D}-\boldsymbol{\sigma}_{D}^{T} \boldsymbol{\sigma}_{D}-\tau^{2} \frac{\lambda}{(1+\lambda)^{2}} \boldsymbol{\Omega}_{0}^{T} \boldsymbol{\Omega}_{0}+o\left(\tau^{2}\right) \\
& =\rho+\mu_{D}-\boldsymbol{\sigma}_{D}^{T} \boldsymbol{\sigma}_{D}-\tau^{2} \frac{\lambda}{(1+\lambda)^{2}}\left[\frac{D_{H}}{S_{H}}-\frac{D_{F}}{S_{F}}\right]\left(\boldsymbol{\sigma}^{T} \boldsymbol{\sigma}\right)^{-1}\left[\begin{array}{c}
\frac{D_{H}}{S_{H}} \\
-\frac{D_{F}}{S_{F}}
\end{array}\right]+o\left(\tau^{2}\right)
\end{aligned}
$$

When markets are imperfectly integrated, the interest rate is below its level of perfect integration: as we already mentionned above, this is due to higher savings for precautionary motive (see figure (4)).

\footnotetext{
${ }^{20}$ In this expression, $y_{F}(\delta)=E_{t}\left[\int_{t}^{\infty} e^{-\rho(s-t)}(1-\delta(s)) d s\right]$ is the present value of current and future contribution of country $F$ in world production.

21 This variable is unfortunately often unobservable: this justifies the use of origin country fixed-effects as in Aviat and Coeurdacier [2004].
} 


\subsection{Excess returns}

To a second order, required excess returns for assets $H$ and $F$ are respectively :

$$
\begin{aligned}
& \mu_{H}-r=\boldsymbol{\sigma}_{H}(\tau) \cdot \boldsymbol{\sigma}_{D}+\tau \frac{\lambda}{1+\lambda} \frac{D_{H}}{S_{H}(\tau)}+o\left(\tau^{2}\right) \\
& \mu_{F}-r=\boldsymbol{\sigma}_{F}(\tau) \cdot \boldsymbol{\sigma}_{D}+\frac{\tau}{1+\lambda} \frac{D_{F}}{S_{F}(\tau)}+o\left(\tau^{2}\right)
\end{aligned}
$$

Since risk-sharing increases as $\tau$ decreases, the required excess return also decreases, as we show below (for the same set of parameters as above).

Our finding that an increase in financial markets integration (a decrease in $\tau$ ) reduces the required excess return is consistent with the empirical evidence (Bekaert et al. [2000] and Henry [2000]). Moreover, we have two additionnal second-order effects on the risk premium (coming through asset prices levels and asset returns volatilities) going in opposite directions. First, since asset prices are lower under imperfect integration, this amplifies the effect of taxes on the risk premium by increasing the after-tax return on home assets required by the foreigners. Second, the decrease in the correlation of stock returns with aggregate output drives the risk premium down.

\subsection{The cost of capital}

We saw that a decrease in $\tau$ causes both an increase in the riskless rate and a decrease in the equilibrium excess returns. The overall impact of a change in $\tau$ on the cost of capital is non monotonous, as shown in figure (6). 


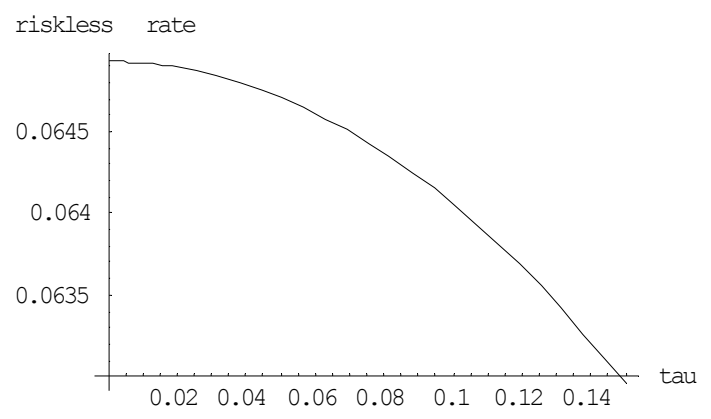

Figure 4 : Riskless rate in the symmetric case as a function of $\tau$. (Calibration $: \rho=0.04$,

$$
\left.\mu_{D_{H}}=\mu_{D_{F}}=0.025, \sigma_{D_{H}, 1}=\sigma_{D_{F}, 2}=0.145, \sigma_{D_{H}, 2}=\sigma_{D_{F}, 1}=0.039\right) .
$$

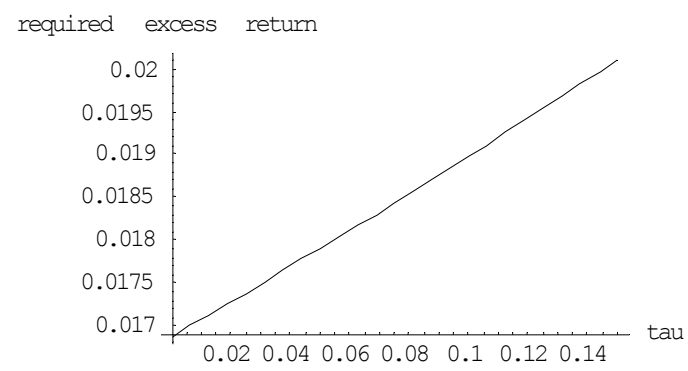

Figure 5 : Excess returns in the symmetric case as a function of $\tau$. (Calibration : $\rho=0.04$, $\left.\mu_{D_{H}}=\mu_{D_{F}}=0.025, \sigma_{D_{H}, 1}=\sigma_{D_{F}, 2}=0.145, \sigma_{D_{H}, 2}=\sigma_{D_{F}, 1}=0.039\right)$.

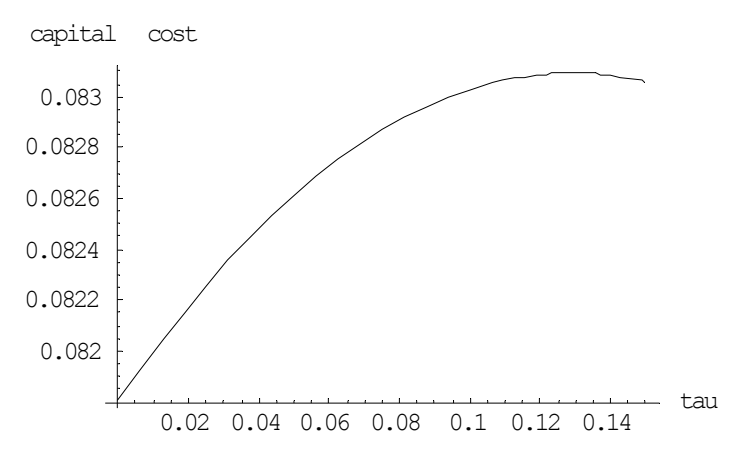

Figure $6:$ Cost of capital in the symmetric case as a function of $\tau$. (Calibration : $\rho=0.04$, $\left.\mu_{D_{H}}=\mu_{D_{F}}=0.025, \sigma_{D_{H}, 1}=\sigma_{D_{F}, 2}=0.145, \sigma_{D_{H}, 2}=\sigma_{D_{F}, 1}=0.039\right)$. 


\section{Comments and discussions}

\subsection{Beyond logarithmic utility}

It could be argued that, assuming log utility, we tackle the case most favorable to getting home bias. But as is well known, assuming power utility with relative risk aversion higher than one would have two effects. For given $\eta_{S}$, a higher risk aversion implies more willingness to diversify, thus reducing home bias. But at the same time, decreasing the elasticity of intertemporal substitution would amplify the impact of endowment shocks on asset prices, thus increasing $\eta_{S}$ for given $\eta$. Indeed, a good dividend shock implies a current increase in consumption and for this increase in consumption to be "accepted" by intertemporally maximizing agents, the interest rate and expected returns must adjust in such a way that increasing consumption now (rather than saving for the future) becomes optimal. This means that expected returns must decrease, which happens through a price increase. The required asset price adjustment is the larger the lower the elasticity of intertemporal substitution. Dumas, Harvey and Ruiz [2002] point to this elasticity as the key preference parameter driving stock return correlations. Overall, assuming power utility with relative risk aversion higher than one would certainly increase return correlations, which would dampen the direct effect of higher risk aversion on the extent of portfolio diversification. The two effects could be disentangled by introducing Epstein-Zin preferences.

\subsection{Imperfect substituability between home and foreign goods}

International asset pricing models typically restrict the commodity market to a single tradable good ${ }^{22}$, and our model is no exception. In other words, it is assumed that home and foreign goods are perfect substitutes. Relaxing this assumption would not change the overall message of our paper, but it would lead to a new component driving asset prices correlations: a "terms of trade effect" (this effect appears in Rigobon and Pavlova [2004], for an elasticity equal to one).

Indeed, assuming perfect goods substituability and no frictions on the international goods markets implies that the terms of trade and the real exchange rate must be constant and equal to one. But as soon as goods produced at home and abroad are imperfect substitutes, the relative price of domestic and

22 Of course, the strand of the literature (following Dellas and Stockman [1989]) that adopts the dichotomy between traded and non-traded goods has more than one good, but still typically has only one type of traded good. The real exchange rate in these models is not constant, but the effect that we have in mind in this section does not show up in these models. 
foreign goods is affected by the relative scarcity of each type of goods: the relative price of a good is negatively related to its abundance (this is a standard feature of Ricardian models of trade). This "terms of trade effect" would play in case of endowment shocks, a good dividend shock being accompanied by a counteracting relative price change, which would make asset prices evolutions more connected.

The strength of this effect decreases with goods substituability. For an elasticity of substitution below one, the effect is so large that a good shock in the home country reduces domestic asset prices and increases foreign asset prices, leading actually to a divergence in returns! In the special case of an elasticity of substitution equal to one (Cobb-Douglas preferences), the "terms of trade effect" exactly cancels out the initial effect of the rise in profits on asset prices, making domestic and foreign assets perfect substitutes. This is exactly what happens in Cole and Obstfeld [1991]: financial diversification is pointless since perfect risk-sharing is achieved through terms of trade movements. In the frictionless case, one can show that the substituability between assets (i.e. their returns correlation) is decreasing with respect to the substituability between goods ${ }^{23}$. In particular, this means that we would get the same level of assets returns correlation for a level of fundamentals correlation lower than what we used in our calibration. We leave a full characterization of the equilibrium with differentiated goods and frictions for future research.

\subsection{Financial frictions vs. trade cost}

Can we interpret our tax on the repatriation of dividends as a trade cost, i.e. as a cost associated with the shipping of goods? First, it is important to notice that if $\tau$ were to be interpreted as a shipping cost, it could not be an iceberg cost, since our tax redistribution amounts to no transfer loss. But even abstracting from the redistribution of taxes, a model with a tax on dividend repatriation and a model with trade costs (Dumas [1992], Sercu [1993], Sercu, Uppal and Van Hulle [1995, 2002]) are not equivalent: indeed, if domestic residents have to pay a trade $\operatorname{cost} \tau$ when shipping goods from abroad, they can save on these costs by exchanging the goods they own abroad against domestic goods owned by foreigners at the equilibrium relative price, the real exchange rate: no shipping costs will be paid as long as foreign and domestic productions are not too asymmetric (or equivalently as long as the real exchange rate is

\footnotetext{
23 This result holds for an elasticity of substitution between home and foreign goods larger than one. A proof is available on request.
} 
between $1-\tau$ and $\frac{1}{1-\tau}$ ). This is a key difference with our setup, in which investors have no other option than repatriating their dividends and paying taxes.

A model with transportation costs could lead to an equilibrium closer to the one we get if an additional friction was introduced in the goods market. Indeed, in Dumas [1992] and the papers that followed, the goods market is perfectly competitive and agents are price-takers. We could relax this assumption and say that domestic agents who own goods abroad (in quantity $q$ ) can either ship the goods by themselves, with proportional costs $T$, or exchange them against home goods with a price-maker retailer at a relative price $\frac{1}{1-\tau}$. As long as $\tau<T$, the domestic resident will choose to sell his goods to the retailer, so that the final quantity of home goods that he can consume from his claim on foreign output is $(1-\tau) q$. In this modified setting with an imperfectly competitive goods market, agents always have to pay the trade cost $\tau$ per unit of goods "shipped" 24 , so that the equilibrium portfolios and asset prices would be in line with those that we found above. Frictions on the goods markets would then be equivalent to frictions on financial markets: in both cases, foreign dividend streams would be less valuable because associated with systematically paid costs $\tau$.

\section{Conclusion}

This paper provides a complete description of the competitive equilibrium prevailing in what we believe to be a benchmark case of imperfectly integrated financial markets. We find our setting appealing as it is all at once simple, empirically relevant and able of accounting for various dimensions of the data.

The technical challenge that we faced and overcame consists in solving for equilibrium with heterogeneous agents, the source of heterogeneity being that, due to differential taxation, investors do not face the same opportunity set (after-tax dividend streams is what matters). In a partial equilibrium sense, our markets are complete: each investor faces a number of independent assets equal to the martingale multiplicity plus one, therefore we could use Cox and Huang [1989], rather than He and Pearson [1991], to solve the individual consumption-portfolio choice problem. But in a general equilibrium sense, it is as

\footnotetext{
24 Note that $\tau$ is not completely unconnected to the effective transport cost $T$ since $\frac{1}{1-T}$ is the maximum relative price that the retailer can charge. Moreover, we have not determined the optimal $\tau$ that retailers would charge but such a $\tau$ exists since when $\tau$ is getting to high, either domestic residents just consume their own production or prefer shipping goods by themselves, which drives profits to zero.
} 
though markets were incomplete. The departure from complete risk-sharing, which materializes in our time-varying relative weight, comes precisely from the fact that due to differential taxation investors do not face the same (after-tax) assets. This is why we refer to Cuoco and He [1994], rather than resorting to a representative agent like in Huang [1987].

In the end, our model is successful at making sense of many aspects of international financial markets and their evolution ${ }^{25}$. We capture the effect of integration (understood as a decrease in $\tau$ ) on asset prices, we show how the CCAPM is modified relative to the fully-integrated case and how the impact of integration on the cost of capital depends on the respective size of opposite effects on the riskless rate and on the risk premium. We got a second-order effect of integration on return volatility and on the correlation of returns, this effect being due to the fact that impediments to cross-border equity holdings prevent "portfolio rebalancing" and dampen comovements of the pricing kernels relevant for each asset. We shall insist on the fact that our specification provides a lower bound on the ability of the model to generate high return correlation. Higher return correlation could be obtained for given fundamental correlation by decreasing the substituability between home and foreign goods and/or by decreasing the elasticity of intertemporal substitution. Whatever its strength, the relationship between return correlation and the degree of financial integration that shows up in our model is a point relevant for any empirical work looking at the impact of the correlation structure of asset returns on international portfolio allocation. Since the integration of financial markets lead simultaneously to higher comovements of stock prices and to higher levels of cross-border equity holdings, one should be very careful in interpreting the impact of the correlation of stock returns on cross-border equity holdings without controlling for the degree of integration between countries: it could create endogeneity issues which should be taken into account (for instance, see Portes and Rey [2005], Coeurdacier and Guibaud [2004] and Chan et al. [2005]).

We believe our model is instrumental in understanding what "financial integration" means - and in making sense of the paradox associated with its measurement. The paradox comes from the fact that attempting to assess the degree of integration does not convey the same impression along every dimensions: portfolio biases point to segmentation, whereas flows, after their dramatic increase, point to

25 As should be conspicuous, our assessment of the impacts of financial integration does not take into account many imperfections that are of high relevance in the real world. 
a high degree of integration ${ }^{26}$. And even though some arbitrage opportunities may still be found, assets are priced internationally. These different "sides" of world financial markets show up in our model.

Frictions on goods markets, in the form of trade costs, is another important characteristic of the real world. We gave some insights on the link between our setup and asset pricing models featuring such frictions (section 4.3). Having such frictions is important to get a realistic behavior of the terms of trade and of the real exchange rate, and it certainly affects portfolio choice, as originally shown in Adler and Dumas [1983], since investors facing different consumption price indices do not face the same real returns distribution for a given menu of nominal assets. Frictions on financial markets and frictions on goods markets are definitely related as emphasized by Obstfeld and Rogoff [2000], though they are not totally equivalent ${ }^{27}$. We sketched how multiple frictions on the goods markets could generate the effects on portfolio composition and asset prices that we naturally obtain in our setup. More work is needed to determine exactly the respective implications of frictions on financial markets and on goods markets and how they do interact.

\footnotetext{
26 We have large flows of trade in assets (which we did not emphasize), because our friction is not a transaction cost.

27 In particular, Uppal [1993] and Sercu, Uppal and van Hulle [2002] show that, in the presence of positive but finite iceberg costs (and a perfectly competitive goods market), portfolio holdings do not exhibit any home bias in the logarithmic utility case, and even show reverse bias with power utility and risk aversion higher than one.
} 


\section{References}

Amadi, A., 2004, "Equity Home Bias: A Disappearing Phenomenon?", Job Market Paper, UC Davis

Aviat, A. and N. Coeurdacier, 2004, "The Geography of International Trade in Goods and Asset Holdings", DELTA WP 2004-10.

Basak, S and M. Gallmeyer, 2003, "Capital Market Equilibrium with Differential Taxation", European Finance Review, 7, 121-159.

H.S. Bhamra, 2004, "International Stock Market Integration: A Dynamic General Equilibrium Approach", mimeo LBS.

Bekaert, G. and C.R. Harvey, 1995, "Time-Varying World Market Integration", Journal of Finance, $50,403-444$.

Bekaert, G., and C. R. Harvey, 2000, "Foreign Speculators and Emerging Equity Markets", Journal of Finance, 55, 564-614.

Black, F., 1974, "International Capital Market Equilibrium with Investment Barriers", Journal of Financial Economics, 1, 337 -352.

Chan, K., Covrig, V.M., Ng, L.K., 2005, "What Determines the Domestic and Foreign Bias? Evidence from Mutual Fund Equity Allocations Worldwide", Journal of Finance, 60, 1495-1534.

Chen, Z., and P. Knez, 1995, "Measurement of Market Integration and Arbitrage", The Review of Financial Studies, 8, 287-325.

Cochrane, J., F. Longstaff and P. Santa Clara, 2003, "Two Trees: Asset Price Dynamics Induced by Market Clearing", Working Paper, University of Chicago.

Coeurdacier, N. and S. Guibaud, 2004, "International Equity Holdings and Stock Returns Correlations: Does Diversification Matter At All for Portfolio Choice?", mimeo DELTA

Cox, J., and C-F. Huang, 1989, "Optimal Consumption and Portfolio Policies when Asset Prices Follow a Diffusion Process", Journal of Economic Theory, 49, 33-83.

Cuoco, D., and H. He, 1994, "Dynamic Equilibrium in Infinite-Dimensional Economies with Incomplete Financial Markets", unpublished manuscript, University of Pennsylvania.

Detemple, J., and S. Murthy, 1997, "Equilibrium Asset Prices and No Arbitrage with Portfolio Constraints", Review of Financial Studies, 10, 1133-1174.

Dumas, B., 1992, "Dynamic equilibrium and the real exchange rate in a spatially separated world", The Review of Financial Studies, 5:153-180.

Dumas, B, R. Harvey and P. Ruiz, 2003, "Are Correlation of Stock Returns Justified by Subsequent Changes in National Outputs?", Journal of International Money and Finance, 22, 777-811.

Dumas, B., and B. Solnik, 1995, "The World Price of Foreign Exchange Risk", Journal of Finance, $50,445-479$

Errunza, V., and E. Losq, 1985, "International Asset Pricing under Mild Segmentation: Theory and Test", Journal of Finance, 40, 105-124.

Errunza, V., and E. Losq, 1989, "Capital Flow Controls, International Asset Pricing, and Investors' Welfare: a Multi-Country Framework", Journal of Finance, 44, 1025-1037.

Eun, C., and S. Jarakiramanan, 1986, "A Model of International Asset Pricing with a Constraint on the Foreign Equity Ownership", Journal of Finance, 41, 1025-1037.

Flood, R. and A. Rose, 2003, "Financial Integration: A New Methodology and an Illustration", NBER Working Paper, 9880 
Forbes, K., and R. Rigobon, 2002, "No Contagion, Only Interdependence: Measuring Stock Market Co-Movements", Journal of Finance, 57, 2223-2261

Frankel, J. and A. Rose, 1998, "The Endogeneity of the Optimum Currency Area Criteria", Economic Journal, Vol. 108, No. 449, 1009-1025.

Frankel, J and A.K. Rose, 2002, "An Estimate of the Effect of Common Currencies on Trade and Income", The Quarterly Journal of Economics, Vol. 117 (2), 437-466.

French, K. and J. Poterba, 1991. "Investor Diversification and International Equity Markets", American Economic Review, Vol. 81 (2), 222-26.

Goetzmann, W., L. Li and K. Rouwenhorst, 2002, "Long-Term Global Market Correlation," Working Paper, Yale University.

Gordon, R.H., J. Hines, 2002, "International taxation", NBER Working Paper 8854.

Henry, P., 2000, "Stock Market Liberalization, Economic Reform and Emerging Market Equity Prices", Journal of Finance, 55, 529-564.

Hau, H., and H. Rey, 2004, "Can Portfolio Rebalancing Explain the Dynamics of Equity Returns, Equity Flows, and Exchange Rates?" NBER Working paper 10476.

Imbs, J., 1999, "Trade, Finance, Specialization and Synchronization", forthcoming in the Review of Economics and Statistics.

Lane, P and G.M. Milesi-Feretti, 2004, "International Investment Patterns", CEPR Discussion Paper, 4499.

Longin, F. and B. Solnik, 2001, "Extreme Correlation of International Equity Returns", Journal of Finance.

Lucas, R., 1978, "Asset Prices in an Exchange Economy", Econometrica, 46, 1429-1445.

Martin, P. and H. Rey, 2000, "Financial Super-Markets: Size Matters for Asset Trade", NBER Working Paper 8476, forthcoming in Journal of International Economics.

Martin, P and H. Rey, 2000, "Financial Integration and Asset Returns", European Economic Review, vol. 44 (7), 1327-1350.

Merton, R, 1971, "Optimum Consumption and Portfolio Rules in a Continuous Time Model", Journal of Economic Theory, 3, 373-413.

Obstfeld M. and K. Rogoff, 2000, "The Six Major Puzzles in International Macroeconomics: Is There a Common Cause?", NBER Macroeconomics Annual.

Obstfeld, M. and A.M. Taylor, 2002, "Globalization and Capital Markets", NBER Working Paper 8846 .

Pavlova, A. and R. Rigobon, 2004, "Asset Prices and Exchange Rates", MIT Sloan Working Paper 4322-03.

Portes, R. and H. Rey, 2005, "The Determinants of Cross-Border Equity Flows", Journal of International Economics, 65(2), 269-296.

Portes, R., Y. Oh and H. Rey, 2001, "Information and Capital Flows: The Determinants of Transactions in Financial Assets", European Economic Review, vol. 45 (4-6), 783-96.

Sercu, P., R. Uppal, C. Van Hulle, 1995, "The Exchange Rate in the Presence of Transaction Costs: Implications for Tests of Purchasing Power Parity", Journal of Finance, Volume 50, Issue 4, 1309-1319.

Sercu, P., R. Uppal, C. Van Hulle, 2002, "International Portfolio Choice and Home Bias: The Effects of Commodity Market Imperfections", Working Paper. 
Serrat, A., 2001, "A Dynamic Equilibrium Model of International Portfolio Holdings", Econometrica, 69, 1467-1489.

Stulz, R., 1999, "Globalization of Equity Markets and the Cost of Capital", prepared for the SBF/NYSE Conference on Global Equity Markets

Uppal, R., 1993, "A General Equilibrium Model of International Portfolio Choice", Journal of Finance, Volume 48, Issue 2, 529-553.

Walti, S, 2004, "The Macroeconomic Determinants of Stock Market Synchronization", mimeo HEI. 


\section{Appendix}

- Proof of proposition 1 (equilibrium as an optimum with stochastic weighting)

Take $\lambda(t)=\frac{\Psi_{H} \xi_{H}(t)}{\Psi_{F} \xi_{F}(t)}$.

FOC and market clearing for goods give the expressions for $C_{H}$ and $C_{F}$ as functions of $D$ and $\lambda$.

The dynamics of $\lambda$ directly follows from Ito's lemma, since we know the processes for the $\xi_{i}$.

To derive the expression for $S_{H}$, we used the fact that (by definition of the state price density)

$$
\begin{aligned}
& \xi_{H}(t) S_{H}(t)=E_{t}\left[\int_{t}^{+\infty} \xi_{H}(s) D_{H}(s) d s\right] \\
\Rightarrow & S_{H}(t)=\frac{1}{\xi_{H}(t)} E_{t}\left[\int_{t}^{+\infty} \xi_{H}(s) D_{H}(s) d s\right]
\end{aligned}
$$

Besides the FOC is

$$
\begin{gathered}
e^{-\rho t} u^{\prime}\left(c_{H}\right)=\Psi_{H} \xi_{H}(t) \\
\Rightarrow \xi_{H}(t)=\frac{1}{\Psi_{H}} e^{-\rho t} u^{\prime}\left(c_{H}\right)=\frac{1}{\Psi_{H}} e^{-\rho t} \frac{1+\lambda(t)}{D(t)}
\end{gathered}
$$

Plugging this into the above expression for $S_{H}(t)$ and simplifying gives the expression in the text.

Idem for $S_{F}(t)$.

To get the expression for the domestic budget constraint, write

$$
\begin{gathered}
E\left[\int_{0}^{+\infty} \xi_{H}(t) \frac{D(t)}{1+\lambda(t)} d t\right]=\xi_{H}(0) \boldsymbol{\alpha}_{H}^{0} \mathbf{S}(0)+E\left[\int_{0}^{+\infty} \xi_{H}(t) e_{H}(t) d t\right] \\
\Rightarrow E\left[\int_{0}^{+\infty} \frac{1}{\Psi_{H}} e^{-\rho t} d t\right]=\xi_{H}(0) \alpha_{H H}^{0} S_{H}(0)+\xi_{H}(0) \alpha_{H F}^{0} S_{F}(0)+E\left[\int_{0}^{+\infty} \frac{1}{\Psi_{H}} e^{-\rho t} \frac{1+\lambda(t)}{D(t)} e_{H}(t) d t\right] \\
\Rightarrow \quad \int_{0}^{+\infty} e^{-\rho t} d t=\frac{1+\lambda(0)}{D(0)}\left\{\alpha_{H H}^{0} \frac{D(0)}{1+\lambda(0)} E\left[\int_{0}^{+\infty} e^{-\rho s}[1+\lambda(s)] \frac{D_{H}(s)}{D(s)} d s\right]\right. \\
\left.+\alpha_{H F}^{0} \frac{\lambda(0) D(0)}{1+\lambda(0)} E\left[\int_{0}^{+\infty} e^{-\rho s} \frac{1+\lambda(s)}{\lambda(s)} \frac{D_{F}(s)}{D(s)} d s\right]\right\} \\
+E\left[\int_{0}^{+\infty} e^{-\rho t} \frac{1+\lambda(t)}{D(t)} e_{H}(t) d t\right] \\
\int_{0}^{+\infty} e^{-\rho t} d t=\alpha_{H H}^{0} E\left[\int_{0}^{+\infty} e^{-\rho s}[1+\lambda(s)] \frac{D_{H}(s)}{D(s)} d s\right]+\alpha_{H F}^{0} \lambda(0) E\left[\int_{0}^{+\infty} e^{-\rho s} \frac{1+\lambda(s)}{\lambda(s)} \frac{D_{F}(s)}{D(s)} d s\right] \\
+E\left[\int_{0}^{+\infty} e^{-\rho t} \frac{1+\lambda(t)}{D(t)} e_{H}(t) d t\right]
\end{gathered}
$$


Finally, we get:

$$
\frac{1}{\rho}=E\left\{\int_{0}^{+\infty} e^{-\rho s}\left[\alpha_{H H}^{0}(1+\lambda(s)) \frac{D_{H}(s)}{D(s)}+\lambda(0) \alpha_{H F}^{0} \frac{1+\lambda(s)}{\lambda(s)} \frac{D_{F}(s)}{D(s)}+(1+\lambda(s)) \frac{e_{H}(s)}{D(s)}\right] d s\right\}
$$

where

$$
e_{H}(s)=\tau_{H} \alpha_{F H}(s) D_{H}(s)
$$

Remark: when $\tau_{H}=\tau_{F}=0, c_{i}(t)=\rho X_{i}(t)$.

In this case, $\lambda=\frac{X_{F}}{X_{H}}=\frac{\Psi_{H} \xi_{H}}{\Psi_{F} \xi_{F}}$ is constant and equal to the wealth ratio.

\section{- Proof of lemma 1 (market prices of risk)}

The outline of the proof is the following: start from FOCs , apply Ito's lemma to both terms and identify diffusion terms, then use market clearing.

The first-order condition (shown in section 2.3) is:

$$
\begin{aligned}
& e^{-\rho t} \frac{1}{c_{H}(t)}=\Psi_{H} \xi_{H}(t) \\
& \Rightarrow-\rho e^{-\rho t} \frac{1}{c_{H}(t)} d t-e^{-\rho t} \frac{1}{c_{H}(t)^{2}} d c_{H}+e^{-\rho t} \frac{1}{c_{H}(t)^{3}} d c_{H}^{2}=-\Psi_{H} \xi_{H}(t)\left[r(t) d t+\boldsymbol{\theta}_{H}^{T}(t) d \mathbf{W}(t)\right]
\end{aligned}
$$

We will use the following notations

$$
d C_{i}=\mu_{C_{i}}() d t+\sigma_{C_{i}}^{T}() d \mathbf{W} \quad i=H, F
$$

Identifying diffusion terms implies:

$$
\begin{aligned}
& -e^{-\rho t} \frac{1}{c_{H}(t)^{2}} \boldsymbol{\sigma}_{c_{H}}(t)=-\Psi_{H} \xi_{H}(t) \boldsymbol{\theta}_{H}(t) \\
& \Rightarrow-e^{-\rho t} \frac{1}{c_{H}(t)^{2}} \boldsymbol{\sigma}_{c_{H}}(t)=-e^{-\rho t} \frac{1}{c_{H}(t)} \boldsymbol{\theta}_{H}(t), \text { using } e^{-\rho t} \frac{1}{c_{H}(t)}=\Psi_{H} \xi_{H}(t) \\
& \Rightarrow \boldsymbol{\sigma}_{c_{H}}(t)=c_{H}(t) \boldsymbol{\theta}_{H}(t)
\end{aligned}
$$

In the same manner, we get $\boldsymbol{\sigma}_{c_{F}}(t)=c_{F}(t) \boldsymbol{\theta}_{F}(t)$

Besides, market clearing implies

$$
\boldsymbol{\sigma}_{C_{H}}()+\boldsymbol{\sigma}_{C_{F}}()=D \boldsymbol{\sigma}_{D}=D\left[\delta(t) \boldsymbol{\sigma}_{D_{H}}+(1-\delta(t)) \boldsymbol{\sigma}_{D_{F}}\right]
$$

So $c_{H}(t) \boldsymbol{\theta}_{H}(t)+c_{F}(t) \boldsymbol{\theta}_{F}(t)=\left[\delta(t) \boldsymbol{\sigma}_{D_{H}}+(1-\delta(t)) \boldsymbol{\sigma}_{D_{F}}\right] D$. 
We can also use: $\boldsymbol{\theta}_{H}-\boldsymbol{\theta}_{F}=\left(\boldsymbol{\sigma}^{T}\right)^{-1}\left[\begin{array}{c}\tau_{H} \frac{D_{H}}{S_{H}} \\ -\tau_{F} \frac{D_{F}}{S_{F}}\end{array}\right]$ and substitute for $\boldsymbol{\theta}_{F}$ to get:

$$
c_{H}(t) \boldsymbol{\theta}_{H}(t)+c_{F}(t) \boldsymbol{\theta}_{H}-c_{F}(t)\left(\boldsymbol{\sigma}^{T}\right)^{-1}\left[\begin{array}{c}
\tau_{H} \frac{D_{H}}{S_{H}} \\
-\tau_{F} \frac{D_{F}}{S_{F}}
\end{array}\right]=D\left[\delta(t) \boldsymbol{\sigma}_{D_{H}}+(1-\delta(t)) \boldsymbol{\sigma}_{D_{F}}\right]
$$

ie (using $\frac{c_{F}}{D}=\frac{\lambda}{1+\lambda}$ )

$$
\boldsymbol{\theta}_{H}(t)=\left[\delta(t) \boldsymbol{\sigma}_{D_{H}}+(1-\delta(t)) \boldsymbol{\sigma}_{D_{F}}\right]+\frac{\lambda(t)}{1+\lambda(t)}\left(\boldsymbol{\sigma}^{T}\right)^{-1}\left[\begin{array}{c}
\tau_{H} \frac{D_{H}}{S_{H}} \\
-\tau_{F} \frac{D_{F}}{S_{F}}
\end{array}\right]
$$

The formula for $\boldsymbol{\theta}_{F}(t)$ follows from the formula for $\boldsymbol{\theta}_{H}-\boldsymbol{\theta}_{F}$.

Remark: the drift and diffusion in the dynamics of $\lambda, \frac{d \lambda}{\lambda}=\mu_{\lambda} d t+\boldsymbol{\sigma}_{\lambda}^{T} d \mathbf{W}$, can be reexpressed:

$$
\begin{aligned}
& \boldsymbol{\sigma}_{\lambda}=\boldsymbol{\theta}_{F}-\boldsymbol{\theta}_{H}=\left(\boldsymbol{\sigma}^{\mathbf{T}}\right)^{-1}\left[\begin{array}{c}
-\tau_{H} \frac{D_{H}}{S_{H}} \\
\tau_{F} \frac{D_{F}}{S_{F}}
\end{array}\right]
\end{aligned}
$$

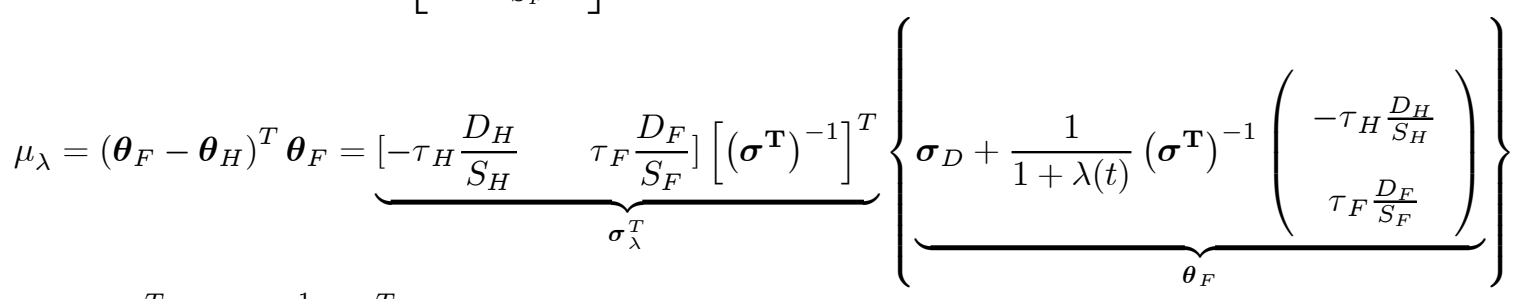

$$
\begin{aligned}
& =\boldsymbol{\sigma}_{\lambda}^{T} \boldsymbol{\sigma}_{D}+\frac{1}{1+\lambda(t)} \boldsymbol{\sigma}_{\lambda}^{T} \boldsymbol{\sigma}_{\lambda} \\
& =\left[-\tau_{H} \frac{D_{H}}{S_{H}} \quad \tau_{F} \frac{D_{F}}{S_{F}}\right]\left[\left(\boldsymbol{\sigma}^{\mathbf{T}}\right)^{-1}\right]^{T} \boldsymbol{\sigma}_{D}+\frac{1}{1+\lambda(t)}\left[-\tau_{H} \frac{D_{H}}{S_{H}} \quad \tau_{F} \frac{D_{F}}{S_{F}}\right]\left[\left(\boldsymbol{\sigma}^{\mathbf{T}}\right)^{-1}\right]^{T}\left(\boldsymbol{\sigma}^{\mathbf{T}}\right)^{-1}\left(\begin{array}{c}
-\tau_{H} \frac{D_{H}}{S_{H}} \\
\tau_{F} \frac{D_{F}}{S_{F}}
\end{array}\right)
\end{aligned}
$$

\section{- Portfolio choice}

We drop subscripts, as the expressions are valid for both investors

$$
\begin{aligned}
\xi(t) X(t)=E_{t}\left[\int_{t}^{\infty} \xi(s)(c(s)-e(s)) d s\right] \\
X(t)=E_{t}\left[\int_{t}^{\infty} \frac{\xi(s)}{\xi(t)}(c(s)-e(s)) d s\right] \\
=E_{t}\left[\int_{t}^{\infty} e^{-\rho(s-t)} \frac{c(t)}{c(s)}(c(s)-e(s)) d s\right] \\
=c(t) E_{t}\left[\int_{t}^{\infty} e^{-\rho(s-t)}\left(1-\frac{e(s)}{c(s)}\right) d s\right] \\
=c(t)\left[\frac{1}{\rho}-E_{t} \int_{t}^{\infty} e^{-\rho(s-t)} \frac{e(s)}{c(s)} d s\right]
\end{aligned}
$$


Since $e_{H}=\tau \alpha_{H}^{F} D_{H}$, we rewrite:

$$
\begin{aligned}
X_{H}(t) & =c_{H}(t)\left[\frac{1}{\rho}-\tau u_{H}(t)\right] \\
& =\frac{1}{\rho} \frac{D(t)}{1+\lambda(t)}\left[1-\tau \rho u_{H}(t)\right]
\end{aligned}
$$

Ito's lemma implies that in $d X_{H}=\mu_{X_{H}} X_{H} d t+X_{H} \boldsymbol{\sigma}_{X_{H}} d \mathbf{W}$

$$
\boldsymbol{\sigma}_{X_{H}}=\boldsymbol{\sigma}_{D}-\frac{\lambda}{1+\lambda} \boldsymbol{\sigma}_{\lambda}+\tau \boldsymbol{\sigma}_{e}
$$

where $\boldsymbol{\sigma}_{e}$ depends on the endowment term $u_{H}$.

Applying the martingale representation theorem like Cox and Huang [1989], we identify diffusion terms in (3) and get the following expressions for the domestic home investor's portfolios:

$$
\begin{aligned}
{\left[\begin{array}{c}
\frac{S_{H} \alpha_{H H}}{X_{H}} \\
\frac{S_{F} \alpha_{H F}}{X_{H}}
\end{array}\right] } & =\boldsymbol{\sigma}^{-1} \boldsymbol{\sigma}_{D}-\frac{\lambda}{1+\lambda} \boldsymbol{\sigma}^{-1} \boldsymbol{\sigma}_{\lambda}+\tau \boldsymbol{\sigma}^{-1} \boldsymbol{\sigma}_{e} \\
& =\boldsymbol{\sigma}^{-1} \boldsymbol{\sigma}_{D}+\frac{\lambda}{1+\lambda}\left(\boldsymbol{\sigma}^{T} \boldsymbol{\sigma}\right)^{-1}\left[\begin{array}{c}
\frac{D_{H}}{S_{H}} \\
-\frac{D_{F}}{S_{F}}
\end{array}\right]+\boldsymbol{\epsilon}_{H} \\
& =\boldsymbol{\sigma}^{-1} \boldsymbol{\theta}_{H}+\boldsymbol{\epsilon}_{H}
\end{aligned}
$$

\section{- Proof of proposition 3 (riskless rate)}

* Start from FOC, apply Ito and identify drift terms:

$$
\begin{aligned}
& e^{-\rho t} \frac{1}{c_{H}(t)}=\Psi_{H} \xi_{H}(t) \\
& \Rightarrow-\rho e^{-\rho t} \frac{1}{c_{H}(t)} d t-e^{-\rho t} \frac{1}{c_{H}(t)^{2}} d c_{H}+e^{-\rho t} \frac{1}{c_{H}(t)^{3}} d c_{H}^{2}=-\Psi_{H} \xi_{H}(t)\left[r(t) d t+\boldsymbol{\theta}_{H}^{T}(t) d \mathbf{W}(t)\right] \text { (Ito) } \\
& \Rightarrow-\rho \frac{1}{c_{H}(t)}-\frac{1}{c_{H}(t)^{2}} \mu_{C_{H}}+\frac{1}{c_{H}(t)^{3}} \boldsymbol{\sigma}_{c_{H}}^{T}(t) \boldsymbol{\sigma}_{c_{H}}(t)=-\frac{1}{c_{H}(t)} r(t) \text { (identification of drift terms) } \\
& \Rightarrow r(t)=\rho+\frac{\mu_{C_{H}}(t)}{c_{H}(t)}-\frac{1}{c_{H}(t)^{2}} \boldsymbol{\sigma}_{c_{H}}^{T}(t) \boldsymbol{\sigma}_{c_{H}}(t)=\rho+\frac{\mu_{C_{H}}(t)}{c_{H}(t)}-\boldsymbol{\theta}_{H}^{T}(t) \boldsymbol{\theta}_{H}(t)
\end{aligned}
$$

where we used $\boldsymbol{\sigma}_{c_{H}}=c_{H} \boldsymbol{\theta}_{H}$ to get the last equation.

In the same way, we get: $r(t)=\rho+\frac{\mu_{C_{F}}(t)}{c_{F}(t)}-\frac{1}{c_{F}(t)^{2}} \boldsymbol{\sigma}_{c_{F}}^{T}(t) \boldsymbol{\sigma}_{c_{F}}(t)=\rho+\frac{\mu_{C_{F}}(t)}{c_{F}(t)}-\boldsymbol{\theta}_{F}^{T}(t) \boldsymbol{\theta}_{F}(t)$

* Summing the two expressions:

$$
r(t)=\rho+\frac{1}{2}\left(\frac{\mu_{C_{H}}(t)}{c_{H}(t)}+\frac{\mu_{C_{F}}(t)}{c_{F}(t)}\right)-\frac{1}{2}\left(\boldsymbol{\theta}_{H}(t) \cdot \boldsymbol{\theta}_{H}(t)+\boldsymbol{\theta}_{F}(t) \cdot \boldsymbol{\theta}_{F}(t)\right)
$$


* Then using market clearing (which implies $\left.\mu_{C_{H}}()+\mu_{C_{F}}()=\mu_{D} D\right)$ and applying Ito's lemma on $D /(1+\lambda)$ to get $\mu_{C_{H}}$, after a bit of algebra, the term $\frac{\mu_{C_{H}}(t)}{c_{H}(t)}+\frac{\mu_{C_{F}}(t)}{c_{F}(t)}$ can be shown to be equal to

$$
2 \mu_{D}+\frac{\lambda-1}{1+\lambda}\left(-\mu_{\lambda}+\frac{\lambda}{1+\lambda} \boldsymbol{\sigma}_{\lambda} \cdot \boldsymbol{\sigma}_{\lambda}-\boldsymbol{\sigma}_{\lambda} . \boldsymbol{\sigma}_{D}\right)
$$

So that the riskless rate can be written

$$
r(t)=\rho+\mu_{D}+\frac{1}{2} \frac{\lambda-1}{1+\lambda}\left(-\mu_{\lambda}+\frac{\lambda}{1+\lambda} \boldsymbol{\sigma}_{\lambda} \cdot \boldsymbol{\sigma}_{\lambda}-\boldsymbol{\sigma}_{\lambda} \cdot \boldsymbol{\sigma}_{D}\right)-\frac{1}{2}\left(\boldsymbol{\theta}_{H}(t) . \boldsymbol{\theta}_{H}(t)+\boldsymbol{\theta}_{F}(t) \cdot \boldsymbol{\theta}_{F}(t)\right)
$$

* By lemma 1, we further know that $\boldsymbol{\theta}_{H}(t)=\boldsymbol{\sigma}_{D}+\frac{\lambda(t)}{1+\lambda(t)}\left(\boldsymbol{\sigma}^{T}\right)^{-1}\left[\begin{array}{c}\tau_{H} \frac{D_{H}}{S_{H}} \\ -\tau_{F} \frac{D_{F}}{S_{F}}\end{array}\right]$, so that

$\boldsymbol{\theta}_{H}(t) \cdot \boldsymbol{\theta}_{H}(t)=\boldsymbol{\sigma}_{D} \cdot \boldsymbol{\sigma}_{D}+\frac{\lambda(t)}{1+\lambda(t)}\left[\begin{array}{ll}\tau_{H} \frac{D_{H}}{S_{H}} & -\tau_{F} \frac{D_{F}}{S_{F}}\end{array}\right] \boldsymbol{\sigma}^{-1} \boldsymbol{\sigma}_{D}+\frac{\lambda(t)}{1+\lambda(t)} \boldsymbol{\sigma}_{D}^{T}\left(\boldsymbol{\sigma}^{T}\right)^{-1}\left[\begin{array}{c}\tau_{H} \frac{D_{H}}{S_{H}} \\ -\tau_{F} \frac{D_{F}}{S_{F}}\end{array}\right]$

$$
+\left(\frac{\lambda(t)}{1+\lambda(t)}\right)^{2}\left[\tau_{H} \frac{D_{H}}{S_{H}} \quad-\tau_{F} \frac{D_{F}}{S_{F}}\right]\left(\boldsymbol{\sigma}^{T} \boldsymbol{\sigma}\right)^{-1}\left[\begin{array}{c}
\tau_{H} \frac{D_{H}}{S_{H}} \\
-\tau_{F} \frac{D_{F}}{S_{F}}
\end{array}\right]
$$

And symmetrically $\boldsymbol{\theta}_{F}=\boldsymbol{\sigma}_{D}-\frac{1}{1+\lambda(t)}\left(\boldsymbol{\sigma}^{\mathbf{T}}\right)^{-1}\left[\begin{array}{c}\tau_{H} \frac{D_{H}}{S_{H}} \\ -\tau_{F} \frac{D_{F}}{S_{F}}\end{array}\right]$, so that

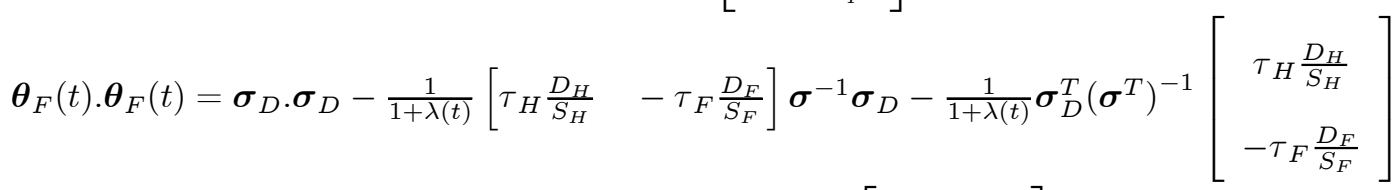

$$
+\left(\frac{1}{1+\lambda(t)}\right)^{2}\left[\tau_{H} \frac{D_{H}}{S_{H}} \quad-\tau_{F} \frac{D_{F}}{S_{F}}\right]\left(\boldsymbol{\sigma}^{T} \boldsymbol{\sigma}\right)^{-1}\left[\begin{array}{c}
\tau_{H} \frac{D_{H}}{S_{H}} \\
-\tau_{F} \frac{D_{F}}{S_{F}}
\end{array}\right]
$$

* Putting the pieces together, we get:

$$
\begin{aligned}
& r(t)=\rho+\mu_{D}-\boldsymbol{\sigma}_{D} \cdot \boldsymbol{\sigma}_{D} \\
& +\frac{1}{2} \frac{\lambda-1}{1+\lambda}\left(-\mu_{\lambda}+\frac{\lambda}{1+\lambda} \boldsymbol{\sigma}_{\lambda} \cdot \boldsymbol{\sigma}_{\lambda}-\boldsymbol{\sigma}_{\lambda} \cdot \boldsymbol{\sigma}_{D}\right) \\
& -\frac{\lambda(t)-1}{1+\lambda(t)}\left[\tau_{H} \frac{D_{H}}{S_{H}} \quad-\tau_{F} \frac{D_{F}}{S_{F}}\right] \boldsymbol{\sigma}^{-1} \boldsymbol{\sigma}_{D}
\end{aligned}
$$

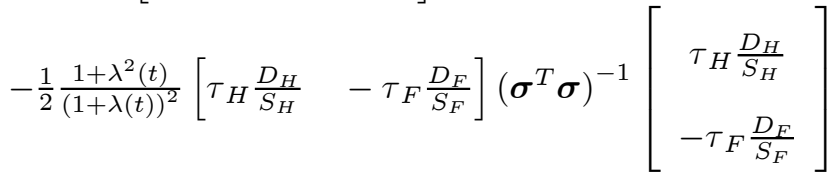

* After a bit of algebra (using the expressions for $\mu_{\lambda}$ and $\sigma_{\lambda}$ given in equation (7)), this expression 
simplifies to

$$
\begin{aligned}
r(t) & =\rho+\mu_{D}-\boldsymbol{\sigma}_{D} \cdot \boldsymbol{\sigma}_{D}-\frac{\lambda}{(1+\lambda)^{2}} \boldsymbol{\sigma}_{\lambda} \cdot \boldsymbol{\sigma}_{\lambda} \\
& =\rho+\mu_{D}-\boldsymbol{\sigma}_{D} \cdot \boldsymbol{\sigma}_{D}-\frac{\lambda}{(1+\lambda)^{2}}\left[\begin{array}{cc}
\tau_{H} \frac{D_{H}}{S_{H}} & -\tau_{F} \frac{D_{F}}{S_{F}}
\end{array}\right]\left(\boldsymbol{\sigma}^{T} \boldsymbol{\sigma}\right)^{-1}\left[\begin{array}{c}
\tau_{H} \frac{D_{H}}{S_{H}} \\
-\tau_{F} \frac{D_{F}}{S_{F}}
\end{array}\right]
\end{aligned}
$$

\section{- Proof of proposition 5 (restriction on price diffusion component)}

Apply Ito's lemma to $S_{H}(t)=\frac{D(t)}{1+\lambda(t)} h(\delta(t), \lambda(t))$ and focusing on the diffusion term gives:

$$
\begin{aligned}
& S_{H} \boldsymbol{\sigma}_{H}^{T}=\frac{1}{1+\lambda}\left[\begin{array}{ll}
h & D\left(h_{\lambda}-\frac{h}{1+\lambda}\right)
\end{array} \quad D h_{\delta}\right]\left[\begin{array}{c}
D \boldsymbol{\sigma}_{D}^{T} \\
\lambda \boldsymbol{\sigma}_{\lambda}^{T} \\
\delta \boldsymbol{\sigma}_{\delta}^{T}
\end{array}\right] \\
& \Rightarrow \frac{D(t)}{1+\lambda(t)} h \boldsymbol{\sigma}_{H}^{T}=\frac{1}{1+\lambda}\left[\begin{array}{lll}
h & D\left(h_{\lambda}-\frac{h}{1+\lambda}\right) & D h_{\delta}
\end{array}\right]\left[\begin{array}{c}
D \boldsymbol{\sigma}_{D}^{T} \\
\lambda \boldsymbol{\sigma}_{\lambda}^{T} \\
\delta \boldsymbol{\sigma}_{\delta}^{T}
\end{array}\right]
\end{aligned}
$$

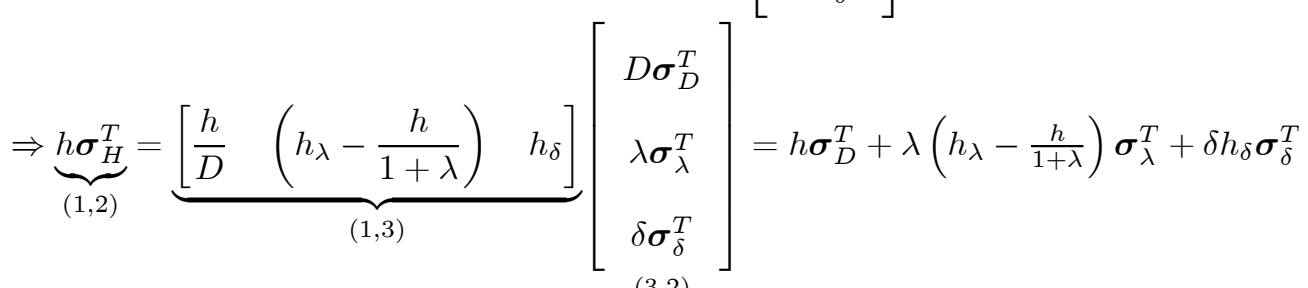

Idem for $S_{F}(t)$,

$$
\begin{aligned}
& S_{F} \boldsymbol{\sigma}_{F}^{T}=\frac{1}{1+\lambda}\left[\begin{array}{lll}
\lambda f & D\left(\lambda f_{\lambda}+\frac{f}{1+\lambda}\right) & \lambda D f_{\delta}
\end{array}\right]\left[\begin{array}{c}
D \boldsymbol{\sigma}_{D}^{T} \\
\lambda \boldsymbol{\sigma}_{\lambda}^{T} \\
\delta \boldsymbol{\sigma}_{\delta}^{T}
\end{array}\right] \\
& \Rightarrow \frac{\lambda(t) D(t)}{1+\lambda(t)} f \boldsymbol{\sigma}_{F}^{T}=\frac{1}{1+\lambda}\left[\begin{array}{lll}
\lambda f & D\left(\lambda f_{\lambda}+\frac{f}{1+\lambda}\right) & \lambda D f_{\delta}
\end{array}\right]\left[\begin{array}{c}
D \boldsymbol{\sigma}_{D}^{T} \\
\lambda \boldsymbol{\sigma}_{\lambda}^{T} \\
\delta \boldsymbol{\sigma}_{\delta}^{T}
\end{array}\right] \\
& \Rightarrow f \boldsymbol{\sigma}_{F}^{T}=\left[\frac{f}{D}\left(f_{\lambda}+\frac{f}{\lambda(1+\lambda)}\right) \quad f_{\delta}\right]\left[\begin{array}{c}
D \boldsymbol{\sigma}_{D}^{T} \\
\lambda \boldsymbol{\sigma}_{\lambda}^{T} \\
\delta \boldsymbol{\sigma}_{\delta}^{T}
\end{array}\right]=f \boldsymbol{\sigma}_{D}^{T}+\lambda\left(f_{\lambda}+\frac{f}{\lambda(1+\lambda)}\right) \boldsymbol{\sigma}_{\lambda}^{T}+\delta f_{\delta} \boldsymbol{\sigma}_{\delta}^{T}
\end{aligned}
$$


- Cochrane functions

$$
\begin{aligned}
y_{H}(\delta) & \equiv E\left[\int_{0}^{\infty} e^{-\rho(s-t)} \delta(s) d s \mid \delta(0)=\delta\right] \\
& =\frac{1}{\psi(1-\gamma)}\left(\frac{\delta}{1-\delta}\right) F\left(1,1-\gamma ; 2-\gamma ; \frac{\delta}{\delta-1}\right)+\frac{1}{\psi \theta} F\left(1, \theta ; 1+\theta ; \frac{\delta-1}{\delta}\right)
\end{aligned}
$$

with $F$ the standard (2,1)-hypergeometric function and

$$
\begin{gathered}
\psi=\sqrt{\nu^{2}+2 \rho \chi^{2}} \\
\gamma=\frac{\nu-\psi}{\chi^{2}} \\
\theta=\frac{\nu+\psi}{\chi^{2}}
\end{gathered}
$$

where

$$
\begin{gathered}
\nu=\mu_{D_{F}}-\mu_{D_{H}}-\frac{\sigma_{D_{F, 1}}^{2}+\sigma_{D_{F, 2}}^{2}}{2}+\frac{\sigma_{D_{H, 1}}^{2}+\sigma_{D_{H, 2}}^{2}}{2} \\
\chi^{2}=\left(\sigma_{D_{H, 1}}^{2}+\sigma_{D_{H, 2}}^{2}\right)+\left(\sigma_{D_{F, 1}}^{2}+\sigma_{D_{F, 2}}^{2}\right)-2\left(\sigma_{D_{H, 1}} \sigma_{D_{F, 1}}+\sigma_{D_{H, 2}} \sigma_{D_{F, 2}}\right)
\end{gathered}
$$

And

$$
\begin{aligned}
y_{F}(\delta) & \equiv E\left[\int_{0}^{\infty} e^{-\rho(s-t)}(1-\delta(s)) d s \mid \delta(0)=\delta\right] \\
& =\frac{1}{\psi(1+\theta)}\left(\frac{1-\delta}{\delta}\right) F\left(1,1+\theta ; 2+\theta ; \frac{\delta-1}{\delta}\right)-\frac{1}{\psi \gamma} F\left(1,-\gamma ; 1-\gamma ; \frac{\delta}{\delta-1}\right)
\end{aligned}
$$

- Lemma for proposition 6 (first-order expansion of $\mu_{\lambda}$ and $\sigma_{\lambda}$ )

We take first-order Taylor expansions of expressions for $\boldsymbol{\sigma}_{\lambda}$ and $\mu_{\lambda}$ around $\tau=0$.

- diffusion

$$
\begin{aligned}
\boldsymbol{\sigma}_{\lambda} & =\tau\left(\boldsymbol{\sigma}_{0}^{T}\right)^{-1}\left[\begin{array}{c}
-\left(\frac{D_{H}}{S_{H}}\right)_{0} \\
\left(\frac{D_{F}}{S_{F}}\right)_{0}
\end{array}\right]+o(\tau) \\
& =\tau \boldsymbol{\Omega}_{0}(\delta)+o(\tau)
\end{aligned}
$$


where we defined

$$
\boldsymbol{\Omega}_{0}(\delta) \equiv\left(\boldsymbol{\sigma}_{0}^{T}\right)^{-1}\left[\begin{array}{c}
-\left(\frac{D_{H}}{S_{H}}\right)_{0} \\
\left(\frac{D_{F}}{S_{F}}\right)_{0}
\end{array}\right]
$$

- drift

$$
\begin{aligned}
\mu_{\lambda} & =\tau\left[-\left(\frac{D_{H}}{S_{H}}\right)_{0}\left(\frac{D_{F}}{S_{F}}\right)_{0}\right] \boldsymbol{\sigma}_{0}^{-1} \boldsymbol{\sigma}_{D}+o(\tau) \\
& =\tau \boldsymbol{\Omega}_{0}^{T} \boldsymbol{\sigma}_{D}+o(\tau)
\end{aligned}
$$

We now want to show that $\boldsymbol{\Omega}_{0}^{T}(\delta) \boldsymbol{\sigma}_{D}(\delta)=\rho(1-2 \delta)$. Substituting the definition of $\boldsymbol{\Omega}_{0}$, we have

$$
\boldsymbol{\Omega}_{0}^{T} \boldsymbol{\sigma}_{D}=\left[-\left(\frac{D_{H}}{S_{H}}\right)_{0}\left(\frac{D_{F}}{S_{F}}\right)_{0}\right]\left(\boldsymbol{\sigma}_{0}\right)^{-1} \boldsymbol{\sigma}_{D}
$$

which implies

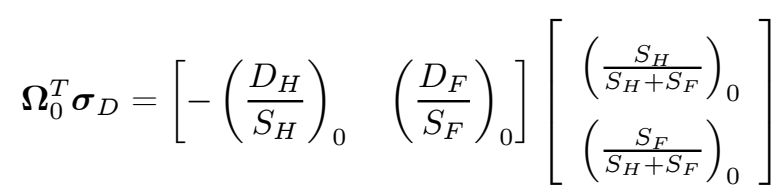

because $\left(\boldsymbol{\sigma}_{0}\right)^{-1} \boldsymbol{\sigma}_{D}$ is exactly the vector of stock holdings of a representative agent in an equilibrium without frictions, which in turn must be equal to the market portfolio. Then, using $\left(S_{H}+S_{F}\right)_{0}=$ $\left(X_{H}+X_{F}\right)_{0}=\frac{D}{\rho}$, we get :

$$
\boldsymbol{\Omega}_{0}^{T} \boldsymbol{\sigma}_{D}=\rho(1-2 \delta)
$$

\section{- Proposition 6 (first-order approximation formula for asset prices)}

* By lemma in section 2.6, $S_{H}(t)=\frac{D(t)}{1+\lambda(t)} h(\delta(t), \lambda(t))$ with

$$
h(\delta(t), \lambda(t))=E\left[\int_{t}^{+\infty} e^{-\rho(s-t)}[1+\lambda(s)] \delta(s) d s \mid \delta(t), \lambda(t)\right]
$$

Since $\frac{d \lambda}{\lambda}=\mu_{\lambda} d t+\sigma_{\lambda}^{\prime} d W$, for $s>t_{0}$

$$
\lambda(s)=\lambda\left(t_{0}\right) \exp \left\{\int_{t_{0}}^{s}\left[\mu_{\lambda}-\frac{1}{2} \boldsymbol{\sigma}_{\lambda} \cdot \boldsymbol{\sigma}_{\lambda}\right] d t+\int_{t_{0}}^{s} \boldsymbol{\sigma}_{\lambda}^{T} d W_{t}\right\}
$$


Besides, we know by lemma that

$$
\begin{gathered}
\boldsymbol{\sigma}_{\lambda}=\tau \boldsymbol{\Omega}_{0}(\delta)+o(\tau) \\
\mu_{\lambda}=\tau \rho(1-2 \delta)+o(\tau)
\end{gathered}
$$

where $\boldsymbol{\Omega}_{0}(\delta)$ is known from Cochrane ${ }^{28}$.

Therefore, introducing $\gamma_{0}(\delta)=\tau \rho(1-2 \delta)$, we can write

$$
\begin{aligned}
& \lambda(s)=\lambda\left(t_{0}\right) \exp \left\{\tau\left[\int_{t_{0}}^{s} \gamma_{0}\left(\delta_{t}\right) d t+\int_{t_{0}}^{s} \Omega_{0}^{T}\left(\delta_{t}\right) d W_{t}\right]+o(\tau)\right\} \\
& \Rightarrow \lambda(s)=\lambda\left(t_{0}\right)\left[1+\tau \int_{t_{0}}^{s} \gamma_{0}\left(\delta_{t}\right) d t+\tau \int_{t_{0}}^{s} \boldsymbol{\Omega}_{0}^{T}\left(\delta_{t}\right) d W_{t}\right]+o(\tau)
\end{aligned}
$$

and

$$
\begin{gathered}
h(\delta(t), \lambda(t))=E_{t}\left\{\int_{t}^{+\infty} e^{-\rho(s-t)}\left[1+\lambda(t)+\tau \lambda(t) \int_{t}^{s} \gamma_{0}\left(\delta_{t^{\prime}}\right) d t^{\prime}+\tau \lambda(t) \int_{t}^{s} \Omega_{0}^{T}\left(\delta_{t^{\prime}}\right) d W_{t^{\prime}}+o(\tau)\right] \delta(s) d s\right\} \\
\Rightarrow \quad h(\delta(t), \lambda(t))=(1+\lambda(t)) E_{t}\left[\int_{t}^{+\infty} e^{-\rho(s-t)} \delta(s) d s\right] \\
+\tau \lambda(t) \underbrace{E_{t}\left[\int_{t}^{+\infty} e^{-\rho(s-t)}\left[\int_{t}^{s} \gamma_{0}\left(\delta_{t^{\prime}}\right) d t^{\prime}+\int_{t}^{s} \Omega_{0}^{T}\left(\delta_{t^{\prime}}\right) d W_{t^{\prime}}\right] \delta(s) d s\right]}_{\equiv-H(\delta(t))}+o(\tau) \\
\Rightarrow h(\delta(t), \lambda(t))=(1+\lambda(t)) y_{H}(\delta(t))-\tau \lambda(t) H(\delta(t))+o(\tau)
\end{gathered}
$$

Then $S_{H}$ and $S_{F}$ are given by

$$
\begin{aligned}
& S_{H}\left(D_{t}, \delta_{t}, \lambda_{t} ; \tau\right)=D_{t}\left[y_{H}\left(\delta_{t}\right)-\tau \frac{\lambda_{t}}{1+\lambda_{t}} H\left(\delta_{t}\right)\right]+o(\tau) \\
& S_{F}\left(D_{t}, \delta_{t}, \lambda_{t} ; \tau\right)=D_{t}\left[y_{F}\left(\delta_{t}\right)-\tau \frac{1}{1+\lambda_{t}} F\left(\delta_{t}\right)\right]+o(\tau)
\end{aligned}
$$

We have to show that functions $H$ and $F$ verify the following boundary value problem

28 It is given by:

$$
\boldsymbol{\Omega}_{0}(\delta) \equiv\left(\boldsymbol{\sigma}_{0}^{T}\right)^{-1}\left[\begin{array}{c}
-\left(\frac{D_{H}}{S_{H}}\right)_{0} \\
\left(\frac{D_{F}}{S_{F}}\right)_{0}
\end{array}\right]
$$




$$
\begin{gathered}
\left\{\begin{array}{c}
\rho H-\delta \mu_{\delta} H^{\prime}-\frac{1}{2} \delta^{2} \boldsymbol{\sigma}_{\delta}^{T} \boldsymbol{\sigma}_{\delta} H^{\prime \prime}=-\left[\rho(1-2 \delta) y_{H}+\left(\boldsymbol{\sigma}_{\delta}^{T} \boldsymbol{\Omega}_{0}\right) y_{H}^{\prime}\right]=\delta \\
H(0)=0 \\
H(1)=\frac{1}{\rho}
\end{array}\right. \\
\left\{\begin{array}{c}
\rho F-\delta \mu_{\delta} F^{\prime}-\frac{1}{2} \delta^{2} \boldsymbol{\sigma}_{\delta}^{T} \boldsymbol{\sigma}_{\delta} F^{\prime \prime}=\rho(1-2 \delta) y_{F}+\left[\boldsymbol{\sigma}_{\delta}^{T} \boldsymbol{\Omega}_{0}\right] y_{F}^{\prime}=1-\delta \\
F(0)=\frac{1}{\rho} \\
F(1)=0
\end{array}\right.
\end{gathered}
$$

* We can then rewrite the PDE for $h$ (equation (9)) by using this first-order approximation and by taking into account that Feynmac-Kac applied to $y_{H}\left(\right.$.) (which implies $\rho y_{H}=(1+\lambda) \delta+\delta \mu_{\delta} y_{H}^{\prime}+$ $\left.\frac{1}{2} \delta^{2}\left(\boldsymbol{\sigma}_{\delta}^{T} \boldsymbol{\sigma}_{\delta}\right) y_{H}^{\prime \prime}\right)$ to get:

$$
\rho H(\delta)=\delta \mu_{\delta} H^{\prime}(\delta)+\frac{1}{2} \delta^{2} \boldsymbol{\sigma}_{\delta}^{T} \boldsymbol{\sigma}_{\delta} H^{\prime \prime}(\delta)-\rho(1-2 \delta) y_{H}(\delta)-\delta\left[\boldsymbol{\sigma}_{\delta}^{T}(\delta) \boldsymbol{\Omega}_{0}(\delta)\right] y_{H}^{\prime}(\delta)
$$

The first boundary condition follows from the fact that given the nature of the dividend process

$$
S_{H}(D, 0, \lambda)=0
$$

The necessity of the second boundary condition can be seen from the fact that it must be the case that

$$
\lim _{\lambda \rightarrow \infty} S_{H}(D, 1, \lambda)=\frac{(1-\tau) D}{\rho}
$$

Indeed, when $\delta$ goes to 1 and $\lambda$ goes to infinity, the economy tends to an economy with one tree only $\left(D=D_{H}\right)$ and one investor located in the foreign country, thus facing an after-tax dividend stream $(1-\tau) D$

* In the same way, we characterize the foreign asset price through a function $F$ solution of a PDE with analogous boundary conditions (see in the text).

* We now prove that the non homogenous terms in the PDEs can be rewritten:

$$
\begin{aligned}
& \rho(1-2 \delta) y_{H}+\delta\left(\boldsymbol{\sigma}_{\delta}^{T} \boldsymbol{\Omega}_{0}\right) y_{H}^{\prime}=-\delta \\
& \rho(1-2 \delta) y_{F}+\delta\left(\boldsymbol{\sigma}_{\delta}^{T} \boldsymbol{\Omega}_{0}\right) y_{F}^{\prime}=1-\delta
\end{aligned}
$$


To do that we use the fact that in the equilibrium without frictions (Cochrane \& al.), the restriction on price diffusion components takes the following form:

$$
\begin{aligned}
\boldsymbol{\sigma}_{H 0} & =\boldsymbol{\sigma}_{D}+\frac{y_{H}^{\prime}}{y_{H}} \delta \boldsymbol{\sigma}_{\delta} \\
\boldsymbol{\sigma}_{F 0} & =\boldsymbol{\sigma}_{D}+\frac{y_{F}^{\prime}}{y_{F}} \delta \boldsymbol{\sigma}_{\delta}
\end{aligned}
$$

Then :

$$
\begin{aligned}
\boldsymbol{\sigma}_{0}^{-1} \boldsymbol{\sigma}_{H 0} & =\boldsymbol{\sigma}_{0}^{-1} \boldsymbol{\sigma}_{D}+\delta \frac{y_{H}^{\prime}}{y_{H}} \boldsymbol{\sigma}_{0}^{-1} \boldsymbol{\sigma}_{\delta} \\
& =\left[\begin{array}{c}
\left(\frac{S_{H}}{S_{H}+S_{F}}\right)_{0} \\
\left(\frac{S_{F}}{S_{H}+S_{F}}\right)_{0}
\end{array}\right]+\delta \frac{y_{H}^{\prime}}{y_{H}} \boldsymbol{\sigma}_{0}^{-1} \boldsymbol{\sigma}_{\delta}
\end{aligned}
$$

where the second equality follows from the fact that in the equilibrium without frictions $\boldsymbol{\sigma}_{0}{ }^{-1} \boldsymbol{\sigma}_{D}$ is exactly the vector of stock holdings of a representative agent, which must be equal to the market portfolio. Symmetrically,

$$
\boldsymbol{\sigma}_{0}^{-1} \boldsymbol{\sigma}_{F 0}=\left[\begin{array}{c}
\left(\frac{S_{H}}{S_{H}+S_{F}}\right)_{0} \\
\left(\frac{S_{F}}{S_{H}+S_{F}}\right)_{0}
\end{array}\right]+\delta \frac{y_{F}^{\prime}}{y_{F}} \boldsymbol{\sigma}_{0}^{-1} \boldsymbol{\sigma}_{\delta} .
$$

Then, since $\boldsymbol{\sigma}_{0}=\left(\begin{array}{ll}\boldsymbol{\sigma}_{H 0} & \boldsymbol{\sigma}_{F 0}\end{array}\right)$ we have :

$$
\begin{aligned}
& \mathbf{I}_{2}=\boldsymbol{\sigma}_{0}^{-1} \boldsymbol{\sigma}_{0}=\left[\begin{array}{cc}
\left(\frac{S_{H}}{S_{H}+S_{F}}\right)_{0} & \left(\frac{S_{H}}{S_{H}+S_{F}}\right)_{0} \\
\left(\frac{S_{F}}{S_{H}+S_{F}}\right)_{0} & \left(\frac{S_{F}}{S_{H}+S_{F}}\right)_{0}
\end{array}\right]+\left[\delta \frac{y_{H}^{\prime}}{y_{H}} \boldsymbol{\sigma}_{0}^{-1} \boldsymbol{\sigma}_{\delta} \quad \delta \frac{y_{F}^{\prime}}{y_{F}} \boldsymbol{\sigma}_{0}^{-1} \boldsymbol{\sigma}_{\delta}\right]
\end{aligned}
$$

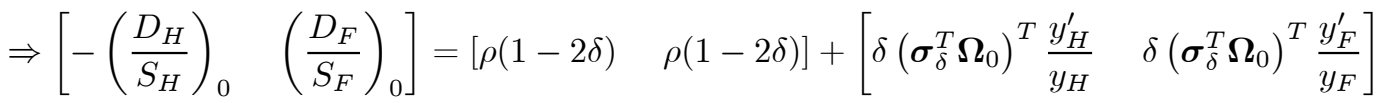

$$
\begin{aligned}
& \Rightarrow\left[-\left(\frac{D_{H}}{S_{H}} y_{H}\right)_{0} \quad\left(\frac{D_{F}}{S_{F}} y_{F}\right)_{0}\right]=\left[\begin{array}{ll}
-\delta & (1-\delta)
\end{array}\right] \\
& =\left[\rho(1-2 \delta) y_{H}+\delta\left(\sigma_{\delta}^{T} \Omega_{0}\right) y_{H}^{\prime} \quad \rho(1-2 \delta) y_{F}+\delta\left(\sigma_{\delta}^{T} \Omega_{0}\right) y_{F}^{\prime}\right]
\end{aligned}
$$

QED. 
Then, it is immediate that $y_{H}$ and $y_{F}$ are solutions of the boundary value problems above (by definition of $y_{H}$ and $\left.y_{F}\right)$.

This gives the first-order development for $S_{H}$ and $S_{F}$ :

$$
\begin{aligned}
& S_{H}\left(D_{t}, \delta_{t}, \lambda_{t} ; \tau\right)=D_{t}\left[1-\tau \frac{\lambda_{t}}{1+\lambda_{t}}\right] y_{H}\left(\delta_{t}\right)+o(\tau) \\
& S_{F}\left(D_{t}, \delta_{t}, \lambda_{t} ; \tau\right)=D_{t}\left[1-\tau \frac{1}{1+\lambda_{t}}\right] y_{F}\left(\delta_{t}\right)+o(\tau)
\end{aligned}
$$

- Lemma for proposition 7 (second-order expansion of $\mu_{\lambda}$ and $\sigma_{\lambda}$ )

* We can easily prove that

$$
\left(\boldsymbol{\sigma}^{T}\right)^{-1}=\left(\boldsymbol{\sigma}_{0}^{T}\right)^{-1}+o(\tau)
$$

* We can also write

$$
\begin{aligned}
\frac{D_{H}}{S_{H}} & =\left(\frac{D_{H}}{S_{H}}\right)_{0}\left[1+\tau \frac{\lambda_{t}}{1+\lambda_{t}}\right]+o(\tau) \\
\frac{D_{F}}{S_{F}} & =\left(\frac{D_{F}}{S_{F}}\right)_{0}\left[1+\frac{\tau}{1+\lambda_{t}}\right]+o(\tau)
\end{aligned}
$$

Indeed

$$
\begin{aligned}
\frac{D_{H}}{S_{H}} & =\frac{D_{H}}{D} \frac{D}{S_{H}} \\
& =\frac{D_{H}}{D} \frac{1}{y_{H}\left(\delta_{t}\right)\left(1-\tau \frac{\lambda_{t}}{1+\lambda_{t}}\right)+o(\tau)} \\
& =\left(\frac{D_{H}}{S_{H}}\right)_{0}+\tau \frac{\lambda_{t}}{1+\lambda_{t}}\left(\frac{D_{H}}{S_{H}}\right)_{0}+o(\tau) \\
\frac{D_{F}}{S_{F}} & =\frac{D_{F}}{D}\left[y_{F}\left(\delta_{t}\right)\left(1-\tau \frac{1}{1+\lambda_{t}}\right)\right]_{0}^{-1} \\
& =\left(\frac{D_{F}}{S_{F}}\right)_{0}+\tau \frac{1}{1+\lambda_{t}}\left(\frac{D_{F}}{S_{F}}\right)_{0}+o(\tau)
\end{aligned}
$$

* Then we can write second-order approximations of the parameters $\mu_{\lambda}$ and $\sigma_{\lambda}$ governing the dynamic of $\lambda$ : 
- diffusion

$$
\begin{aligned}
\boldsymbol{\sigma}_{\lambda} & =\tau\left(\boldsymbol{\sigma}_{0}^{\mathbf{T}}\right)^{-1}\left(\begin{array}{c}
-\frac{D_{H}}{S_{H}} \\
\frac{D_{F}}{S_{F}}
\end{array}\right) \\
& =\tau \boldsymbol{\Omega}_{0}+\tau^{2} \boldsymbol{\Omega}_{1}+o\left(\tau^{2}\right)
\end{aligned}
$$

with : $\boldsymbol{\Omega}_{1}=\frac{1}{1+\lambda}\left(\boldsymbol{\sigma}_{0}^{\mathbf{T}}\right)^{-1}\left(\begin{array}{c}-\lambda\left(\frac{D_{H}}{S_{H}}\right)_{0} \\ \left(\frac{D_{F}}{S_{F}}\right)_{0}\end{array}\right)$

- drift

$$
\begin{aligned}
\mu_{\lambda} & =\boldsymbol{\sigma}_{\lambda}^{T} \boldsymbol{\sigma}_{D}+\frac{1}{1+\lambda(t)} \boldsymbol{\sigma}_{\lambda}^{T} \boldsymbol{\sigma}_{\lambda} \\
& =\tau \boldsymbol{\Omega}_{0}^{T} \boldsymbol{\sigma}_{D}+\tau^{2}\left(\boldsymbol{\Omega}_{1}^{T} \boldsymbol{\sigma}_{D}\right)+\tau^{2} \frac{1}{1+\lambda}\left(\boldsymbol{\Omega}_{0}^{T} \boldsymbol{\Omega}_{0}\right)+o\left(\tau^{2}\right) \\
& =\tau \rho(1-2 \delta)+\tau^{2}\left(\boldsymbol{\Omega}_{1}^{T} \boldsymbol{\sigma}_{D}\right)+\tau^{2} \frac{1}{1+\lambda}\left(\boldsymbol{\Omega}_{0}^{T} \boldsymbol{\Omega}_{0}\right)+o\left(\tau^{2}\right) \\
& =\tau \rho(1-2 \delta)+\tau^{2}\left[\frac{\rho}{1+\lambda}-\rho \delta+\frac{1}{1+\lambda}\left(\boldsymbol{\Omega}_{0}^{T} \boldsymbol{\Omega}_{0}\right)\right]+o\left(\tau^{2}\right)
\end{aligned}
$$

* To complete the proof and get the final expression for $\mu_{\lambda}$, we just have to reexpress $\Omega_{1}^{T} \boldsymbol{\sigma}_{D}$. Just as for the first order approximation :

$$
\begin{aligned}
\Omega_{1}^{T} \boldsymbol{\sigma}_{D} & =\frac{1}{1+\lambda}\left(-\lambda\left(\frac{D_{H}}{S_{H}}\right)_{0} \quad\left(\frac{D_{F}}{S_{F}}\right)_{0}\right)\left(\boldsymbol{\sigma}_{0}\right)^{-1} \boldsymbol{\sigma}_{D} \\
& =\frac{\rho}{1+\lambda}(-\lambda \delta+1-\delta) \\
& =\frac{\rho}{1+\lambda}-\rho \delta
\end{aligned}
$$

\section{- Proof of proposition 7 (second order approximation of asset prices)}

* We work on $h(\delta, \lambda) \equiv E\left[\int_{t}^{+\infty} e^{-\rho(s-t)}[1+\lambda(s)] \delta(s) d s \mid \delta(t)=\delta, \lambda(t)=\lambda\right]$. Like in section 3.1, we show that a second-order approximation of $h$ is given by

$$
h(\delta, \lambda ; \tau)=(1+\lambda) y_{H}(\delta)-\tau \lambda y_{H}(\delta)+\tau^{2} \lambda H_{2}(\delta, \lambda)+o\left(\tau^{2}\right)
$$


* Plugging into the PDE for h (equation 9) and identifying second-order terms, we get the following PDE for $\mathrm{H}_{2}$

$$
\begin{aligned}
\rho H_{2}= & \delta \mu_{\delta} \frac{\partial H_{2}}{\partial \delta}+\frac{1}{2} \delta^{2}\left(\boldsymbol{\sigma}_{\delta}^{T} \boldsymbol{\sigma}_{\delta}\right) \frac{\partial^{2} H_{2}}{\partial \delta^{2}} \\
& +\left[\frac{\rho}{1+\lambda}-\rho \delta+\frac{1}{1+\lambda}\left(\boldsymbol{\Omega}_{0}^{T} \boldsymbol{\Omega}_{0}\right)-\rho(1-2 \delta)\right] y_{H}+\delta\left(\boldsymbol{\sigma}_{\delta}^{T} \boldsymbol{\Omega}_{1}-\boldsymbol{\sigma}_{\delta}^{T} \boldsymbol{\Omega}_{0}\right) y_{H}^{\prime}
\end{aligned}
$$

* We now want to simplify the expression for the non-homogenous term. We already know that : $-\left[\rho(1-2 \delta) y_{H}+\delta \boldsymbol{\sigma}_{\delta}^{T} \boldsymbol{\Omega}_{0} y_{H 0}^{\prime}\right]=\delta$. We are going to show that :

$$
\left(\frac{\rho}{1+\lambda}-\rho \delta\right) y_{H}+\delta\left(\boldsymbol{\sigma}_{\delta}^{T} \boldsymbol{\Omega}_{1}\right) y_{H}^{\prime}=-\frac{\lambda}{1+\lambda} \delta
$$

We use the same reasoning as for the first-order approximation :

$$
\begin{aligned}
& \mathbf{I}_{2}=\boldsymbol{\sigma}_{0}^{-1} \boldsymbol{\sigma}_{0}=\left[\begin{array}{cc}
\left(\frac{S_{H}}{S_{H}+S_{F}}\right)_{0} & \left(\frac{S_{H}}{S_{H}+S_{F}}\right)_{0} \\
\left(\frac{S_{F}}{S_{H}+S_{F}}\right)_{0} & \left(\frac{S_{F}}{S_{H}+S_{F}}\right)_{0}
\end{array}\right]+\left[\delta \frac{y_{H}^{\prime}}{y_{H}} \boldsymbol{\sigma}_{0}^{-1} \boldsymbol{\sigma}_{\delta} \quad \delta \frac{y_{F}^{\prime}}{y_{F}} \boldsymbol{\sigma}_{0}^{-1} \boldsymbol{\sigma}_{\delta}\right]
\end{aligned}
$$

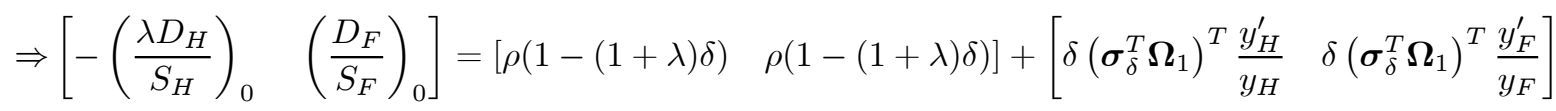

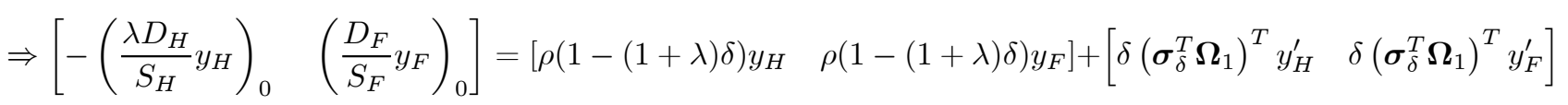

$$
\begin{aligned}
& \Rightarrow \frac{1}{1+\lambda}[-\lambda \delta \quad 1-\delta]=\frac{1}{1+\lambda}\left[\rho(1-(1+\lambda) \delta) y_{H}+\delta\left(\boldsymbol{\sigma}_{\delta}^{T} \boldsymbol{\Omega}_{1}\right)^{T} y_{H}^{\prime} \quad \rho(1-(1+\lambda) \delta) y_{F}+\delta\left(\boldsymbol{\sigma}_{\delta}^{T} \boldsymbol{\Omega}_{1}\right)^{T} y_{F}^{\prime}\right]
\end{aligned}
$$

* Hence, by rewriting the non-homogenous term in the PDE for $H_{2}$, we get :

$$
\rho H_{2}=\delta \mu_{\delta} \frac{\partial H_{2}}{\partial \delta}+\frac{1}{2} \delta^{2}\left(\boldsymbol{\sigma}_{\delta}^{T} \boldsymbol{\sigma}_{\delta}\right) \frac{\partial^{2} H_{2}}{\partial \delta^{2}}+\frac{1}{1+\lambda} \delta+\frac{1}{1+\lambda}\left(\boldsymbol{\Omega}_{0}^{T} \boldsymbol{\Omega}_{0}\right) y_{H}
$$

* Then, we can show that there exists a function $h_{2}$ such that $H_{2}(\delta, \lambda)=\frac{1}{1+\lambda}\left[y_{H}(\delta)+h_{2}(\delta)\right]$ and $h_{2}$ verifies :

$$
\rho h_{2}=\delta \mu_{\delta} h_{2}^{\prime}+\frac{1}{2} \delta^{2}\left(\boldsymbol{\sigma}_{\delta}^{T} \boldsymbol{\sigma}_{\delta}\right) h_{2}^{\prime \prime}+\left(\boldsymbol{\Omega}_{0}^{T} \boldsymbol{\Omega}_{0}\right) y_{H}
$$


(we just use the following property : $\rho y_{H}=\delta \mu_{\delta} y_{H}^{\prime}+\frac{1}{2} \delta^{2}\left(\boldsymbol{\sigma}_{\delta}^{T} \boldsymbol{\sigma}_{\delta}\right) y_{H}^{\prime \prime}+\delta$

* Respectively for $f$, we can show that

$$
f(\delta, \lambda ; \tau)=\frac{1+\lambda}{\lambda} y_{F}(\delta)-\frac{\tau}{\lambda} y_{F}(\delta)+\frac{\tau^{2}}{\lambda} F_{2}(\delta, \lambda)+o\left(\tau^{2}\right)
$$

with $F_{2}(\delta, \lambda)$ satisfying the following differential equation

$$
\rho F_{2}=\delta \mu_{\delta} \frac{\partial F_{2}}{\partial \delta}+\frac{1}{2} \delta^{2}\left(\boldsymbol{\sigma}_{\delta}^{T} \boldsymbol{\sigma}_{\delta}\right) \frac{\partial^{2} F_{2}}{\partial \delta^{2}}+\rho(1-2 \delta) y_{F}-\left[\frac{\rho}{1+\lambda}-\rho \delta\right] y_{F}+\delta\left(\boldsymbol{\sigma}_{\delta}^{T} \boldsymbol{\Omega}_{0}\right) y_{F}^{\prime}-\delta\left(\boldsymbol{\sigma}_{\delta}^{T} \boldsymbol{\Omega}_{1}\right) y_{F}^{\prime}+\frac{\lambda}{1+\lambda}\left(\boldsymbol{\Omega}_{0}^{T} \boldsymbol{\Omega}_{0}\right) y_{F}
$$

And we can rewrite the non-homogenous term in this PDE using

$$
\rho(1-2 \delta) y_{F}+\delta\left(\boldsymbol{\sigma}_{\delta}^{T} \boldsymbol{\Omega}_{0}\right) y_{F}^{\prime}=1-\delta
$$

and

$$
\frac{1}{1+\lambda}\left[\rho(1-(1+\lambda) \delta) y_{F}\right]+\frac{1}{1+\lambda} \delta\left(\boldsymbol{\sigma}_{\delta}^{T} \boldsymbol{\Omega}_{1}\right)^{T} y_{F}^{\prime}=\frac{1-\delta}{1+\lambda}
$$

to obtain

$$
\rho F_{2}=\delta \mu_{\delta} \frac{\partial F_{2}}{\partial \delta}+\frac{1}{2} \delta^{2}\left(\boldsymbol{\sigma}_{\delta}^{T} \boldsymbol{\sigma}_{\delta}\right) \frac{\partial^{2} F_{2}}{\partial \delta^{2}}+(1-\delta) \frac{\lambda}{1+\lambda}+\frac{\lambda}{(1+\lambda)}\left(\boldsymbol{\Omega}_{0}^{T} \boldsymbol{\Omega}_{0}\right) y_{F}
$$

We then introduce the function $f_{2}$ such that $F_{2}(\delta, \lambda)=\frac{\lambda}{1+\lambda}\left[y_{F}(\delta)+f_{2}(\delta)\right]$ and show that it is solution of the ODE given in the text.

\section{* Boundary Conditions}

At this stage, we know that

$$
\begin{aligned}
& S_{H}(D, \delta, \lambda ; \tau)=D\left[y_{H}(\delta)\left(1-\tau \frac{\lambda}{1+\lambda}+\tau^{2} \frac{\lambda}{(1+\lambda)^{2}}\right)+\tau^{2} \frac{\lambda}{(1+\lambda)^{2}} h_{2}(\delta)\right]+o\left(\tau^{2}\right) \\
& S_{F}(D, \delta, \lambda ; \tau)=D\left[y_{F}(\delta)\left(1-\tau \frac{1}{1+\lambda}+\tau^{2} \frac{\lambda}{(1+\lambda)^{2}}\right)+\tau^{2} \frac{\lambda}{(1+\lambda)^{2}} f_{2}(\delta)\right]+o\left(\tau^{2}\right)
\end{aligned}
$$

The conditions $h_{2}(0)=f_{2}(1)=0$ are required since the price of non-existing assets must be zero. The derivation of the other two boundary conditions (on $h_{2}(1)$ and $f_{2}(0)$ ) is more tricky.

When $\delta \rightarrow 1, S_{H}(t)$ tends to 


$$
\frac{D_{H}(t)}{1+\lambda_{t}} E\left[\int_{t}^{+\infty} e^{-\rho(s-t)}[1+\lambda(s)] d s \mid \lambda(t)\right]
$$

Let us define $\phi\left(\lambda_{t} ; \tau\right) \equiv E\left[\int_{t}^{+\infty} e^{-\rho(s-t)}[1+\lambda(s)] d s \mid \lambda(t)\right]$, so that $\lim _{\delta \rightarrow 1} S_{H}(D, \delta, \lambda ; \tau)=\frac{D}{1+\lambda} \phi\left(\lambda_{t} ; \tau\right)$.

Using Feynman-Kac :

$$
\rho \phi(\lambda)=(1+\lambda)+\lambda \bar{\mu}_{\lambda} \phi^{\prime}(\lambda)+\frac{1}{2} \lambda^{2} \overline{\boldsymbol{\sigma}}_{\lambda} \cdot \overline{\boldsymbol{\sigma}}_{\lambda} \phi^{\prime \prime}(\lambda)
$$

where $\bar{\mu}_{\lambda}=\lim _{\delta \rightarrow 1}\left(\mu_{\lambda}\right)$ and $\overline{\boldsymbol{\sigma}}_{\lambda}=\lim _{\delta \rightarrow 1}\left(\boldsymbol{\sigma}_{\lambda}\right)$, i.e.

$$
\begin{gathered}
\overline{\boldsymbol{\sigma}}_{\lambda}=\tau \boldsymbol{\Omega}_{0}(1)+\tau^{2} \boldsymbol{\Omega}_{1}(1) \\
\bar{\mu}_{\lambda}=-\tau \rho+\tau^{2}\left[-\frac{\lambda \rho}{1+\lambda}+\frac{1}{1+\lambda}\left(\boldsymbol{\Omega}_{0}^{T}(1) \boldsymbol{\Omega}_{0}(1)\right)\right]
\end{gathered}
$$

Besides, we know that $h_{2}$ is such that at the second-order in $\tau$ :

$$
h(\delta, \lambda)=(1+\lambda) y_{H}(\delta)-\tau \lambda y_{H}(\delta)+\tau^{2} \frac{\lambda}{1+\lambda}\left[y_{H}(\delta)+h_{2}(\delta)\right]
$$

Taking the limit when $\delta$ goes to 1 , we get

$$
\lim _{\delta \rightarrow 1} h(\delta, \lambda)=\phi(\lambda)=\frac{1}{\rho}\left[1+\lambda-\tau \lambda+\tau^{2} \frac{\lambda}{(1+\lambda)}+\tau^{2} \frac{\lambda}{(1+\lambda)} \rho h_{2}(1)\right]
$$

From this, we can compute $\phi^{\prime}(\lambda)$ and $\phi^{\prime \prime}(\lambda)$ and plug the expressions for $\phi$ and its derivatives in equation (17). Then, identifying second-order terms in the differential equation, we get :

$$
\begin{gathered}
\frac{\lambda}{1+\lambda} \rho h_{2}(1)=\frac{1}{\rho} \frac{\lambda}{1+\lambda}\left(\boldsymbol{\Omega}_{0}^{T}(1) \boldsymbol{\Omega}_{0}(1)\right) \\
\Rightarrow h_{2}(1)=\frac{1}{\rho^{2}} \boldsymbol{\Omega}_{0}^{T}(1) \boldsymbol{\Omega}_{0}(1)
\end{gathered}
$$

Symmetrically :

$$
f_{2}(0)=\frac{1}{\rho}\left(1+\frac{1}{\rho} \boldsymbol{\Omega}_{0}^{T}(0) \boldsymbol{\Omega}_{0}(0)\right)
$$


- Proof of proposition 8 (second order approximation of price diffusion)

We start from proposition 5

$$
\boldsymbol{\sigma}_{H}=\boldsymbol{\sigma}_{D}+\delta \frac{h_{\delta}}{h} \boldsymbol{\sigma}_{\delta}+\lambda\left(\frac{h_{\lambda}}{h}-\frac{1}{1+\lambda}\right) \boldsymbol{\sigma}_{\lambda}
$$

From $h(\delta, \lambda)=(1+\lambda) y_{H}(\delta)-\tau \lambda y_{H}(\delta)+\tau^{2} \frac{\lambda}{1+\lambda} h_{2}(\delta)$, we get the following second order approximations:

$$
\begin{aligned}
\frac{1}{h} & =\frac{1}{(1+\lambda) y_{H}}\left[1+\tau \frac{\lambda}{1+\lambda}-\tau^{2} \frac{\lambda}{(1+\lambda)^{2}} \frac{h_{2}}{y_{H}}\right] \\
h_{\delta} & =(1+\lambda) y_{H}^{\prime}-\tau \lambda y_{H}^{\prime}+\tau^{2} \frac{\lambda}{1+\lambda} h_{2}^{\prime} \\
h_{\lambda} & =y_{H}-\tau y_{H}+\tau^{2} \frac{h_{2}}{(1+\lambda)^{2}}
\end{aligned}
$$

Then, using $\boldsymbol{\sigma}_{\lambda}=\tau \boldsymbol{\Omega}_{0}+\tau^{2} \boldsymbol{\Omega}_{1}$, we compute $\boldsymbol{\sigma}_{H}$ by retaining only terms of order less or equal to 2 :

$$
\boldsymbol{\sigma}_{H}=\boldsymbol{\sigma}_{H 0}+\tau^{2} \frac{\lambda}{(1+\lambda)^{2}}\left\{-\boldsymbol{\Omega}_{0}+\left[\frac{h_{2}^{\prime}}{y_{H}}-\lambda \frac{y_{H}^{\prime}}{y_{H}}-\frac{h_{2} y_{H}^{\prime}}{\left(y_{H}\right)^{2}}\right] \delta \boldsymbol{\sigma}_{\delta}\right\}
$$

In the same way, starting from $\boldsymbol{\sigma}_{F}=\boldsymbol{\sigma}_{D}+\delta \frac{f_{\delta}}{f} \boldsymbol{\sigma}_{\delta}+\lambda\left(\frac{f_{\lambda}}{f}+\frac{1}{\lambda(1+\lambda)}\right) \boldsymbol{\sigma}_{\lambda}$, we get

$$
\boldsymbol{\sigma}_{F}=\boldsymbol{\sigma}_{F 0}+\tau^{2} \frac{\lambda}{(1+\lambda)^{2}}\left\{\boldsymbol{\Omega}_{0}+\left[\frac{f_{2}^{\prime}}{y_{F}}-\frac{1}{\lambda} \frac{y_{F}^{\prime}}{y_{F}}-\frac{f_{2} y_{F}^{\prime}}{\left(y_{F}\right)^{2}}\right] \delta \boldsymbol{\sigma}_{\delta}\right\}
$$

\section{- Approximate portfolio choice}

$$
\begin{aligned}
e_{H} & =\tau \alpha_{H}^{F} D_{H} \\
& =\tau \frac{D_{H}}{S_{H}} \alpha_{H}^{F} S_{H}
\end{aligned}
$$

$\alpha_{H}^{F} S_{H}$ is the amount that foreign investors invest in the domestic asset. At the first order, investors 
hold the world market portfolio, therefore:

$$
\begin{gathered}
e_{H}=\tau \frac{D_{H}}{S_{H}} \frac{S_{H}}{S_{H}+S_{F}} X_{F}+o(\tau) \\
=\tau \frac{D_{H}}{S_{H}+S_{F}} X_{F}+o(\tau) \\
=\tau \frac{D_{H}}{D} \frac{D}{S_{H}+S_{F}} X_{F}+o(\tau) \\
=\tau \delta \rho X_{F}+o(\tau) \\
X_{H}(t)=c_{H}(t)\left[\frac{1}{\rho}-E_{t} \int_{t}^{\infty} e^{-\rho(s-t)} \frac{e_{H}(s)}{c_{H}(s)} d s\right] \\
X_{H}(t)=c_{H}(t)\left[\frac{1}{\rho}-\tau E_{t} \int_{t}^{\infty} e^{-\rho(s-t)} \delta(s) \frac{\rho X_{F}(s)}{c_{H}(s)} d s\right]+o(\tau) \\
c_{H}=\frac{D}{1+\lambda} \text { and } X_{F}=\frac{\lambda}{1+\lambda}\left(X_{H}+X_{F}\right)+o(\tau) \\
\frac{\rho X_{F}}{c_{H}}=\rho \frac{\lambda X_{H}}{c_{H}}+o(\tau) \\
=\lambda+o(\tau)
\end{gathered}
$$

Since for $s>t, \lambda(s)=\lambda(t)+o(\tau)$, we get

$$
X_{H}(t)=c_{H}(t)[\frac{1}{\rho}-\tau \lambda_{t} \underbrace{E_{t} \int_{t}^{\infty} e^{-\rho(s-t)} \delta(s) d s}_{\equiv y_{H}(\delta(t))}]+o(\tau)
$$

From this, we can derive (identifying diffusion terms)

$$
\left[\begin{array}{c}
\frac{S_{H} \alpha_{H H}}{X_{H}} \\
\frac{S_{F} \alpha_{H F}}{X_{H}}
\end{array}\right]=\boldsymbol{\sigma}^{-1} \boldsymbol{\sigma}_{D}+\tau \frac{\lambda}{1+\lambda}\left(\boldsymbol{\sigma}^{T} \boldsymbol{\sigma}\right)^{-1}\left[\begin{array}{c}
\frac{D_{H}}{S_{H}} \\
-\frac{D_{F}}{S_{F}}
\end{array}\right]+\boldsymbol{\epsilon}_{H}
$$

where : $\boldsymbol{\epsilon}_{H}=\tau \lambda \frac{S_{H} S_{F}}{\left(S_{H}+S_{F}\right)^{2}}\left[\begin{array}{c}-1 \\ 1\end{array}\right]$

Respectively: $\boldsymbol{\epsilon}_{F}=\tau \frac{1}{\lambda} \frac{S_{H} S_{F}}{\left(S_{H}+S_{F}\right)^{2}}\left[\begin{array}{c}-1 \\ 1\end{array}\right]$ 